\title{
Estudiantes extranjeros en la UNPA UARG durante el Siglo XXI. Identidad territorial en Río Gallegos
}

\author{
Foreign students at UNPA UARG during the $21^{\text {st }}$ century. Territorial identity in Río \\ Gallegos
}

\author{
María Fernanda García, Cristian Ampuero, Alicia P. Cáceres \\ gmfernanda@outlook.com, campuero@uarg.unpa.edu.ar, acaceres@uarg.unpa.edu.ar \\ Grupo de Investigación y Extensión Z. Terra Cognita \\ Instituto de Ciencias del Ambiente, Sustentabilidad y Recursos Naturales (ICASUR) \\ Universidad Nacional de la Patagonia Austral - Unidad Académica Río Gallegos \\ Av. Gregores y Piloto “Lero" Rivera S/N, Río Gallegos, Santa Cruz, Argentina
}

Recibido: 03/04/2020. Aceptado: 11/09/2020

\begin{abstract}
RESUMEN
El presente trabajo corresponde al informe final de la beca de investigación para alumnos avanzados UNPA, período 2019, de la estudiante de la carrera Licenciatura en Trabajo Social de la UNPA UARG María Fernanda García. El objetivo es presentar los resultados del proceso de investigación sobre la identidad territorial de los estudiantes extranjeros latinoamericanos, que estudian carreras de pregrado, grado y posgrado en la UARG-UNPA. La metodología se basa en el marco teórico y conceptual que aporta la Geografía Cultural, donde la herramienta para obtener la información es la encuesta. Esta investigación surge porque desde los inicios del siglo XXI, se manifiesta de manera relevante, la llegada a Río Gallegos de inmigrantes latinoamericanos -bolivianos, paraguayos, peruanos, colombianos, dominicanos y venezolanos-. Estos inmigrantes, se establecen en la ciudad y desarrollan prácticas culturales diversas (religiosidad popular, fiestas y bailes, gastronomía, asociaciones étnicas, comerciales), que se traducen en prácticas espaciales, que generan identidad territorial. Los resultados fueron tratados estadísticamente.
\end{abstract}

Palabras clave: Inmigración latinoamericana; Estudiantes universitarios; Patagonia Austral Argentina.

\begin{abstract}
This paper corresponds to the final report for the research assistantship for advanced students at UNPA in 2019, from Maria Fernanda Garcia, Social Work Bachelor's Degree student at UNPA UARG. The purpose of this paper is to present the results of the research about the territorial identity of foreign Latin-American undergraduate and graduate students in UNPA UARG. We are basing the study in the theoretical and conceptual framework from the cultural geography, using poll as the main tool to obtain data. The inception of the present study is the immigration of Latin-American people (Bolivians, Paraguayans, Peruvians, Colombians, Dominicans, and Venezuelans) to Rio Gallegos at the beginning of the XXI century. Said immigrants settled in the city and started developing different kinds of cultural practices (religious affairs, festivities, and dances, gastronomy, ethnic associations, commerce) that translated to spatial practices that generate territorial identity. The results were statistically analyzed.
\end{abstract}


Keywords: Latin-American Immigration; University Students; Argentine Austral Patagonia.

\section{Introducción}

El presente trabajo muestra los resultados del proceso de investigación realizado por María Fernanda García, en el marco de una beca de investigación para alumnos avanzados, en este caso, de la carrera Licenciatura en Trabajo Social de la Universidad Nacional de la Patagonia Austral, Unidad Académica Río Gallegos (UNPA UARG), período 2019, dirigida Cristian Ampuero y codirigida por Alicia P. Cáceres. El plan de la beca, denominada "Estudiantes extranjeros en la UNPA UARG durante el siglo XXI. Identidad territorial en Río Gallegos", se enmarca en el Proyecto de Investigación 29/A428 "Migraciones internacionales e identidad territorial en la ciudad de Río Gallegos en el siglo XXI, Patagonia Austral Argentina”, el cual es dirigido por Alicia. P. Cáceres y codirigido por Cristian Ampuero, radicado en la UNPA UARG.

La ciudad de Río Gallegos, desde sus inicios -fines del siglo XIX-, ha sido receptora de flujos migratorios atraídos, entre otras causas, por distintas oportunidades laborales. La misma experimentó dos oleadas migratorias que han dejado su identidad territorial como impronta en el espacio geográfico de la ciudad.

Políticas Nacionales de carácter migratorias permiten que extranjeros obtengan radicación y nacionalidad argentina de forma rápida, razón por la cual acceden a trabajos en dependencias estatales. Paralelamente, en el mismo siglo, la Universidad Nacional de la Patagonia Austral (UNPA) como universidad pública, incorpora a las carreras de grado y pregrado, carreras de posgrado, como especializaciones, maestrías y doctorados, que se dictan en las Unidades Académicas de Río Gallegos y Caleta Olivia.

La combinación de ambas situaciones, favorece el ingreso de estudiantes extranjeros a la UNPA UARG, algunos porque deciden iniciar y/o continuar su formación académica, otros porque arriban expresamente a estudiar en esta universidad. Esta población, desarrolla prácticas culturales diversas, destacándose la religiosidad popular, fiestas y bailes, gastronomía, asociaciones étnicas, que se traducen en prácticas espaciales, conformando la identidad territorial.

Por lo expuesto, el objetivo general del plan de trabajo de la Beca de Investigación fue analizar la identidad territorial de los estudiantes extranjeros que estudian en la UNPA UARG, teniendo en cuenta sus estrategias sociales y culturales, productoras de cohesión territorial que se traducen en prácticas socioespaciales y que permiten conocer e identificar los "lugares" de los estudiantes extranjeros de la UNPA UARG, en los cuales se genera la identidad territorial.

\section{Marco de referencia}

\subsection{Histórico - Geográfico}

La ciudad de Río Gallegos, capital de la Provincia de Santa Cruz, se encuentra ubicada según

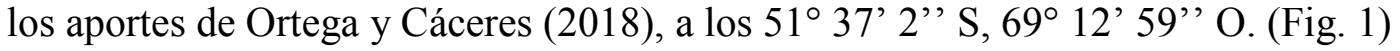


La Situación de Río Gallegos, según Cáceres et al (2016) puede ser estudiada en la historia a partir de tres cortes temporales que dan cuenta del contexto particular de la ciudad:

- 1920 a 1960: situación de encrucijada de ejes de comunicaciones de cabotaje asociados a la producción ganadera y minera;

- 1960 a 2000: situación de encrucijada de ejes de comunicaciones a la producción minera, la administración pública y el turismo;

- 2000 a la actualidad: situación de encrucijada de ejes de comunicaciones asociados a la producción minera y la administración pública.

Asimismo, para Cáceres et al (1996) al estar situada al sureste de la provincia de Santa Cruz y del país, su posición es austral, extrema y periférica.

Según Ampuero et al (2012), en relación a las corrientes migratorias que se establecieron en Río Gallegos, manifiesta que la primera de ellas, a finales del siglo XIX y principios del XX es la migración europea, la cual manifiesta su identidad territorial en el Área Central de la ciudad, expresada en su arquitectura derivada de la migración inglesa denominada "pionera" y la segunda es la migración chilena, la cual comienza a llegar a la Río Gallegos masivamente desde la década de 1960 a 1980, asociadas, “...no sólo a dificultades económicas y sociales, sino a la restricción de las libertades políticas, que alcanzó su máxima expresión con la instalación de la dictadura, además de fenómenos naturales como el terremoto que azotó el Sur de Chile en el año 1960, y que manifiesta su identidad territorial en la Segunda Franja Residencial, específicamente en los barrios Nuestra Señora del Carmen y Belgrano." (Ampuero et al, 2012)
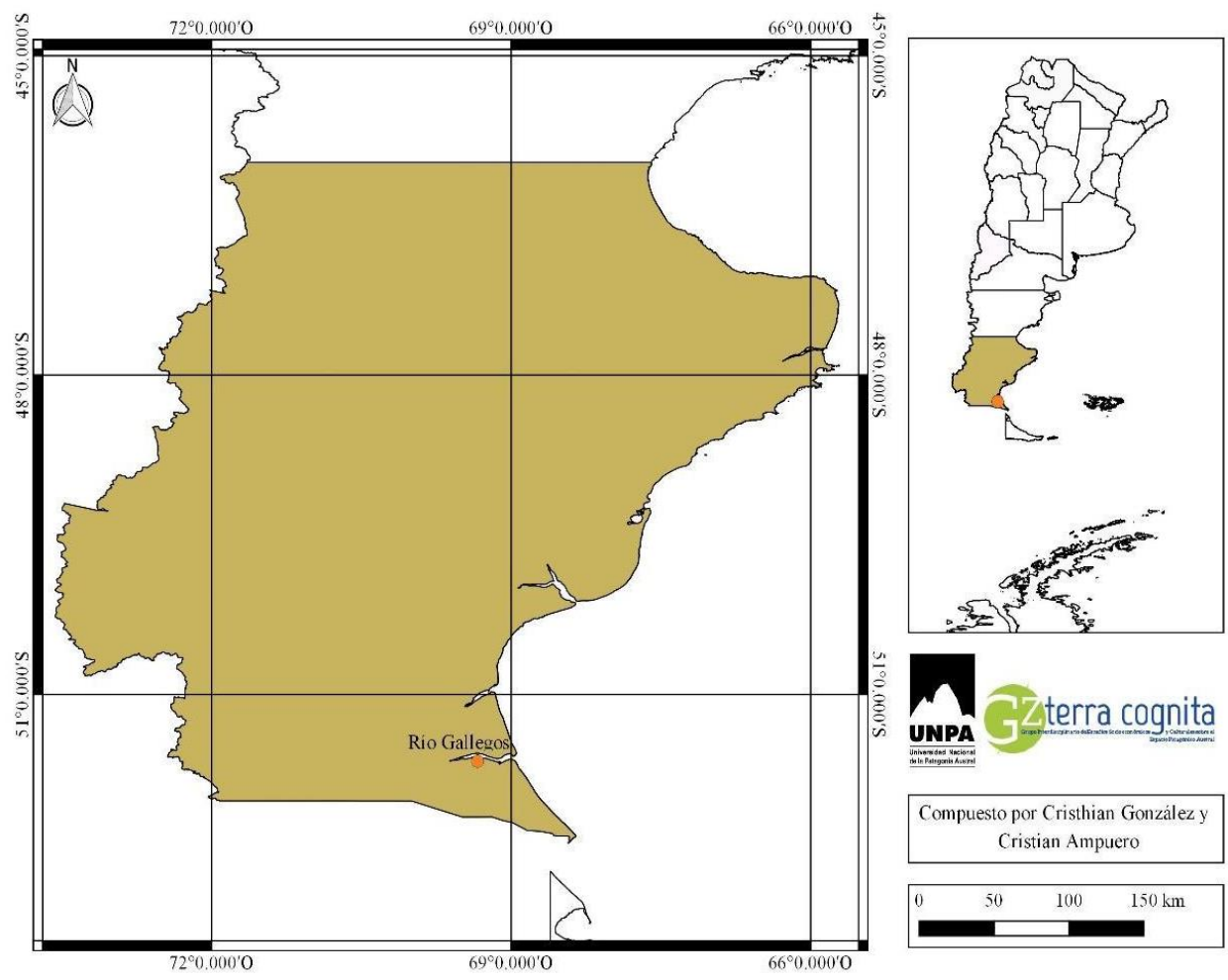

Fig. 1. Posición Geográfica de la ciudad de Río Gallegos. Fuente: González et al (2019)

Dadas las características culturales de la población inmigrante chilena, que aportó a la configuración de estos espacios bien definidos y que ayudaron al surgimiento y crecimiento de la ciudad de Río Gallegos, se estampó una impronta que aún en el presente es visible, por 
ejemplo, a través de su arquitectura. (Ampuero et al, 2012; Norambuena et al, 2014; Norambuena et al, 2018; Ampuero et al, 2019)

Según Ampuero et al (2019), “...en la primera década del siglo XXI comienza a manifestarse de manera más relevante la llegada y asentamiento permanente de inmigrantes bolivianos y paraguayos a la ciudad de Río Gallegos. En los últimos años se registra, además, la llegada de población de nacionalidad colombiana, dominicana y venezolana, asociada a las crisis políticas y socioeconómicas que atraviesan estos países. Este flujo de migración reciente que se radica en la ciudad genera una dinámica en distintos aspectos, como, por ejemplo, en las manifestaciones culturales propias de los grupos de inmigrantes." (Ampuero et al, 2019)

Como se señaló, este trabajo tiene como finalidad analizar la identidad territorial de los estudiantes extranjeros que estudian en la UNPA UARG. Para ello, se deberá tener en cuenta la presencia migratoria en la población universitaria del Campus Universitario de la UNPA UARG.

Asimismo, para describir al Campus Universitario de la UNPA UARG, se recurre a las palabras de Ortega y Cáceres (2018) quienes manifiestan que "El Campus Universitario es un extenso predio de $7000 \mathrm{~m}^{2}$ de superficies cubiertas emplazadas en el espacio verde de 20 hectáreas, se compone de varios edificios e instalaciones. El edificio principal comprende aulas; laboratorios de informática, química, enfermería, recursos naturales y cartografía y teledetección; box de investigación y extensión; Salón de Usos Múltiples (SUM); dependencias de gestión (Secretaría Académica, Investigación y Posgrado, Extensión y Dirección de Bienestar Universitario); Sala de Conferencias "Iris Bergero", oficina de los gremios docente ADIUNPA y no docente ATUNPA y buffet. En el sector exterior se localizan la Biblioteca Malvina Perazo; el centro de educación preescolar Jardín Maternal; el complejo deportivo de Recreación y Deportes, Residencia Universitaria para estudiantes de interior que se encuentran cursando sus estudios en esta ciudad; pista de atletismo; edificio de la Fundación UNPA y la sede de la obra social de la UNPA, OSUNPA.” (Ortega y Cáceres; 2018:35).

Por otro lado, es necesario destacar la oferta académica que tiene la UNPA UARG, la cual se compone de 3 carreras de pregrado: Tecnicaturas Universitarias en Turismo, Acompañante Terapéutico y Gestión de las Organizaciones; 16 carreras de grado: Ingeniería en Recursos Naturales Renovables, Ingeniería Química, Licenciatura en Enfermería, Licenciatura en Psicopedagogía, Licenciatura en Trabajo Social, Licenciatura en Comunicación Social, Licenciatura en Administración, Profesorado en Matemática, Profesorado en Historia, Profesorado/ Licenciatura en Letras, Profesorado/ Licenciatura en Geografía, Licenciatura en Turismo, Profesorado en Economía y Gestión de Organizaciones y Analista/ Licenciatura en Sistemas.

\subsection{Marco Teórico - Conceptual}

El abordaje teórico y metodológico se realiza desde la perspectiva de la Geografía Cultural, debido a que permite el análisis de las representaciones sociales que se dan en el territorio y permite profundizar acerca de la significación que le otorgan los inmigrantes.

A través de la Geografía Cultural, en palabras de Fernández Christlieb (2006) “...no sólo se estudian los aspectos culturales del espacio, sino también el espacio visto a través de los cristales de las diferentes culturas." (Fernández Christlieb; 2006:220) 
Claval (1999), por su parte, sostiene que la Geografía Cultural sirve para “(...) aprehender los procesos culturales verdaderamente significativos, los geógrafos se basan en la experiencia de la gente, en sus contactos, sus formas de hablar. Así descubren cómo las actitudes cambian y los objetos colectivos se construyen a partir de las interacciones. (...)" (Claval; 1999:32)

De acuerdo a la mencionada perspectiva se puede arribar a que la misma, ayuda a tener una lectura de la realidad, por medio del conocimiento y análisis de las diversas culturas migrantes, que se entrecruzan en un mismo espacio, modificándolo.

El estudio del fenómeno de la migración ha crecido en los últimos años, por la permanente transformación de los territorios en base a factores diversos que atraviesan la vida cotidiana de los sujetos, que los impulsa a tomar la decisión de migrar hacia otros espacios, en vista de tener una mejor calidad de vida.

Al hablar de migración se hace referencia, según lo que propone Abu-Warda (2007) a la "movilidad geográfica de personas" (Abu-Warda; 2007:34), donde se debe hacer una diferenciación entre las dimensiones que esta comprende, es decir, por un lado, se encuentra la emigración, que significa la salida de las personas de un país, y por el otro la inmigración, que refiere a la llegada de estas personas al lugar de destino.

La movilidad humana no sólo transforma a la persona que migra, sino que tiene un impacto en la conformación del territorio, donde da paso a nuevas relaciones entre los habitantes y los lugares que lo conforman.

Según Sánchez Ayala (2012) este fenómeno crea sistemas y redes migratorias, lo que da paso a una nueva percepción del espacio, donde se entrecruzan culturas, creencias y modos de vida. Entonces, las personas que deciden migrar a otros territorios no dejan de lado lo aprehendido y adquirido en términos culturales de su lugar de procedencia, por lo que esto luego se traduce en diversas manifestaciones compuestas por festividades y celebraciones que le son propias que demuestran y/o configuran una nueva identidad cultural.

Por otro lado, se debe arribar a la noción de territorio que según Reyes Tovar y Martínez Ruíz (2015) es un "referente geográfico que le da sentido al sujeto y que al mismo tiempo es investido de sentido por él en una forma de correlación y codependencia, creando una imagen del territorio como dinámica y en constante construcción y/o traducción física y simbólica." (Reyes Tovar y Martínez Ruíz; 2015:123)

Es por ello, necesario comprender este término a fin de arribar al fenómeno migratorio y cómo este influye en él. Esto refiere a su vez a una "apropiación social del espacio" en palabras de Reboratti (2001), citado por Reyes Tovar y Martínez Ruíz (2015:123), es decir, que cada sujeto le da una impronta según la conformación de su historia y sus creencias.

Asimismo, de acuerdo con Giménez (1996) el territorio no ha de ser un espacio indiferente o neutral, por el contrario, funciona como un escenario donde se lleva a cabo la acción social, es decir, los sujetos que allí habitan conforman su vida social y cotidiana por lo que es un espacio netamente valorizado de manera instrumental y cultural.

No se debe pasar por alto que esto también se da a partir del reconocimiento del proceso de territorialidad, donde retomando a las autoras Reyes Tovar y Martínez Ruíz (2015) señalan que el mismo se da a partir de un trinomio dialéctico entre sujeto-territorio-patrimonio 
geográfico, esto remite a que esta vinculación permite una continua transformación en la visión y significación del espacio que se intensifica también por los movimientos migratorios. Hasta aquí, resulta necesario comprender que la migración tiene una fuerte relación con conceptos como identidad y cultura, donde estos influyen en la conformación del territorio. Esto permitirá luego comprender mejor a la identidad territorial.

El término identidad, en palabras de Tamayo Vásquez (2011), "es el sentido de pertenencia a una colectividad, a un sector social o un grupo específico de referencia.(...) Así, la identidad puede manifestarse a través de patrimonio cultural, cuya existencia es independiente de su reconocimiento o valoración. (...).” (Tamayo Vásquez; 2011:186-187)

Por este motivo, la identidad forma parte de la historia de los territorios donde se van entretejiendo sentidos en los sujetos de manera individual y colectiva, esta última refuerza la percepción del espacio tanto físico como social, y esta significación es inseparable a la reproducción de los lazos culturales.

Al hablar de cultura, Gravano (2006) considera que la misma “(...) es el conjunto de operaciones simbólicas y prácticas mediante las cuales el hombre está en el mundo transformándolo, produciéndolo como un mundo específicamente humano. Es el conjunto de prácticas y representaciones simbólicas mediante las cuales, una determinada sociedad, grupo u organización, la gente, los pueblos, los sectores sociales, dan sentido, en forma compartida (aún dentro de la heterogeneidad de intereses y valores determinados por la estructura social), a la acciones y actividades que realizan." (Gravano; 2006:93)

Entonces, la cultura se relaciona con el universo de sentido de los sujetos de manera individual y colectiva que es aprendida mediante la imposición. Esta, funciona para delimitar formas y símbolos particulares que se toman como modelos para el aspecto relacional que configuran la cohesión social, es decir, que esto a su vez se da mediante los sujetos conjugados por su historia y el medio ambiente.

Habiendo retomado los conceptos previos, se puede arribar concretamente a qué refiere la identidad cultural donde en palabras de Tamayo Vásquez ésta (2011) “(...) encierra un sentido de pertenencia a un grupo social con el cual se comparten rasgos culturales, como costumbres, valores y creencias. (...) se define históricamente a través de múltiples aspectos en los que plasma su cultura, como la lengua (...), las relaciones sociales, los ritos y ceremonias propias o los comportamientos colectivos que se traducen en los sistemas de valores y creencias (...)." (Tamayo Vásquez; 2011:187)

El proceso migratorio da paso a una nueva conformación del territorio donde la persona migrante no se despoja de su impronta cultural, sino que establece una relación con su medio y sus pares que forma una nueva práctica y significación por medio del lenguaje, diversas celebraciones y creencias que tiene correlación a lo que se conoce como identidad territorial. $\mathrm{Al}$ respecto, Sassone (2007) sostiene que:

“ (...) desde la perspectiva geográfica, la construcción cultural supone agentes activos en la organización espacial, cuyas acciones se diferencian por su estatus social, su estatus económico o estatus étnico. De ese modo, se va edificando un ámbito territorial donde las experiencias de vida del grupo social se expresan en artefactos u objetos materiales, en signos y símbolos, en significados y valores que hacen diferente un territorio de otro y van dando conformidad a la identidad territorial." (Sassone; 2007:14) 


\subsection{Marco Metodológico}

La presente investigación se encuentra regida por los lineamientos que propone la perspectiva de la Geografía Cultural, debido a que la misma da paso a la comprensión del impacto y apropiación del territorio mediante la variable cultural por medio del proceso migratorio.

Por ende, la metodología adoptada es de tipo cuantitativa, con el fin de cuantificar a la población de estudiantes extranjeros de la UNPA-UARG y analizar las siguientes variables censales: edad, nacionalidad y carrera de grado a la cual pertenece. Dado a que permite visualizar cómo se encuentra compuesto este grupo, para luego arribar a aquellos aspectos que refieren a la apropiación y/o relación con el espacio mediante la cultura ya sea dentro del espacio universitario en primera instancia como en la ciudad, entendiendo que dicha información aporta al análisis de la identidad territorial planteado en los objetivos.

Primeramente, se realizó la búsqueda, lectura y análisis de material bibliográfico acorde al tema seleccionado, que permitió la elaboración del marco teórico, trabajando conceptos como: migración, cultura, identidad, identidad territorial, entre otras, que son los más relevantes para la investigación.

Posteriormente, se confeccionó el instrumento de recolección de datos, es decir, la encuesta, que fue aplicada a los estudiantes extranjeros pertenecientes a la UNPA-UARG, con la finalidad de comprobar la hipótesis de trabajo: los estudiantes extranjeros de la UNPA-UARG no poseen una identidad territorial definida, porque no se identifican con los grupos migrantes de su nacionalidad. La encuesta, en este caso, es utiilizada como estrategia para caracterizar y obtener información general de la población migrante.

Para la realización del cuestionario de la encuesta, se formularon preguntas cerradas y abiertas. El mismo se estructuró en cuatro grandes ejes, en los cuales se indaga sobre: variables censales de los estudiantes extranjeros; aspectos relacionados con la residencia en la ciudad de Río Gallegos; vida académica; y, por último, lugares de intercambio social y cultural en la ciudad.

La información relacionada a los estudiantes extranjeros, fueron proporcionados por el Departamento de Alumnos y Estudios, dependiente de la Secretaría Académica de la UNPA UARG. La información provista constó de cantidad de estudiantes extranjeros que son alumnos regulares para el año 2019, donde se registran fechas de ingreso desde el año 2000 al 2019. Se decidió, en concordancia con los objetivos de la investigación, que el análisis se centrara en los estudiantes inscriptos a partir del año 2018.

Se aplicó un muestreo de carácter estratificado bietápico, con el fin de asegurar la presencia de todas las carreras y nacionalidades al momento del relevamiento, es decir un estrato por carreras y otro estrato nacionalidad. De acuerdo al número total de ellos, se decidió encuestar al 50\% del total. El universo total de estudiantes extranjeros en la UNPA UARG fueron 53, donde han sido encuestados 27 estudiantes, por el procedimiento explicado previamente.

Asimismo, para reunir la información necesaria para la aplicación de encuesta se diseñó una planilla Excel que sirvió para establecer los estratos entre los estudiantes extranjeros pertenecientes a la Unidad Académica Río Gallegos, es por ello que a los mismos, se los clasificó primeramente por carrera de grado y luego por nacionalidad debido a que esto permite un control en la aplicación del instrumento de recolección de datos, por lo cual 
también fue fundamental implementar una selección de forma aleatoria, en aquellas carreras con varios inscriptos, para poder cumplimentar con toda la población objetivo.

Por último, los datos obtenidos en las encuestas, fueron procesados con el software estadístico SPSS, para elaborar gráficos y tablas síntesis resultantes de confrontar las variables planteadas.

\subsection{Resultados}

\section{Resultados, Análisis y Discusión}

Los resultados obtenidos a partir de la aplicación de la encuesta refieren, en una primera instancia, al eje de variables censales, tales como: edad, género, nacionalidad, nivel de estudios alcanzados, estado civil y ocupación de los estudiantes extranjeros que se forman en la UNPA UARG. A continuación, se detallan dichos resultados.

Primeramente, en lo que refiere a la edad de los estudiantes, los resultados demuestran que dicha población objetivo tiene la característica de ser predominantemente joven, es decir, las franjas etarias con mayor porcentaje tienen entre 21 y 30 años, mientras que en un número inferior se presentan también estudiantes con menor edad que la detallada y adultos. (Fig. 2)

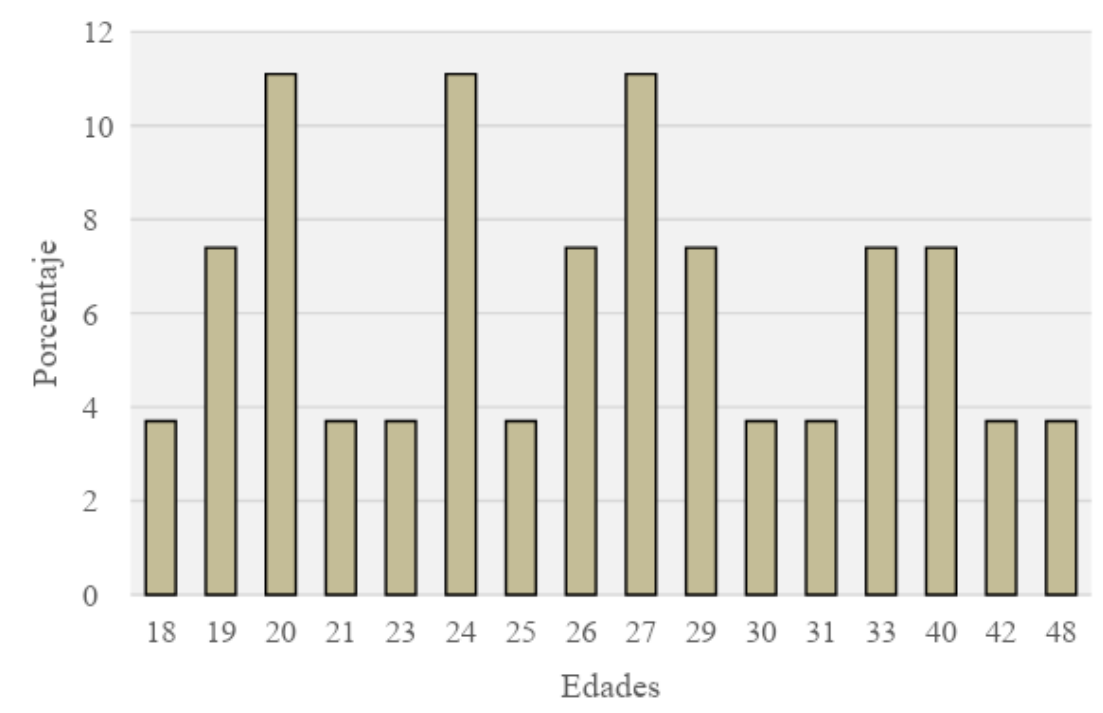

Fig. 2. Edad de estudiantes extranjeros en la UNPA-UARG. Fuente: Elaboración propia.

De acuerdo al género (Fig. 3) de los estudiantes predomina el femenino en un porcentaje del $70,4 \%$ y luego el masculino con un $29,6 \%$. 


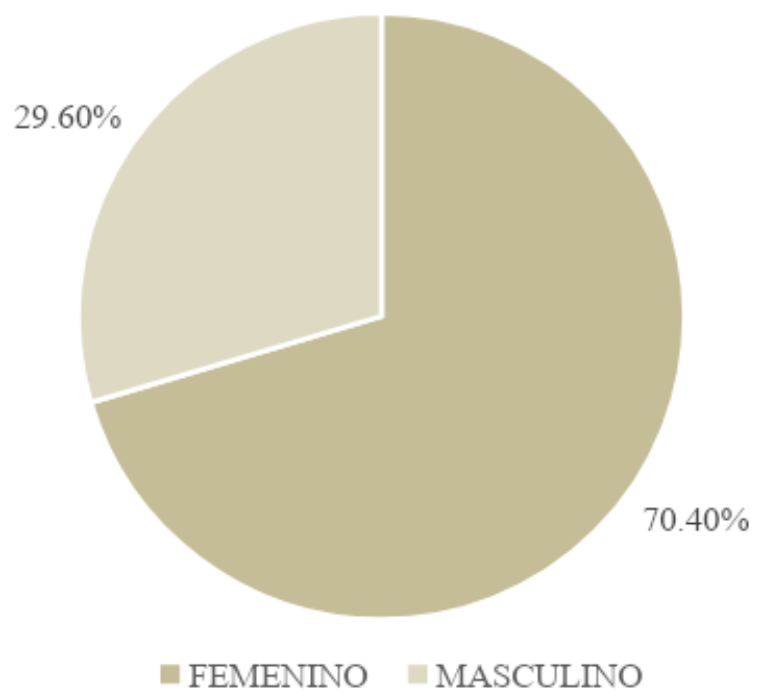

Fig. 3. Género de estudiantes extranjeros en la UNPA-UARG. Fuente: Elaboración propia.

En lo que respecta a la nacionalidad (Fig. 4) se observa que hay mayor porcentaje de estudiantes provenientes de Chile en un 44,4\%, luego Bolivia y Paraguay con un 18,5\%, teniendo una cifra menor República Dominicana con $7,4 \%$ y por último Cuba, Ecuador y Perú en un $3,7 \%$ cada uno.

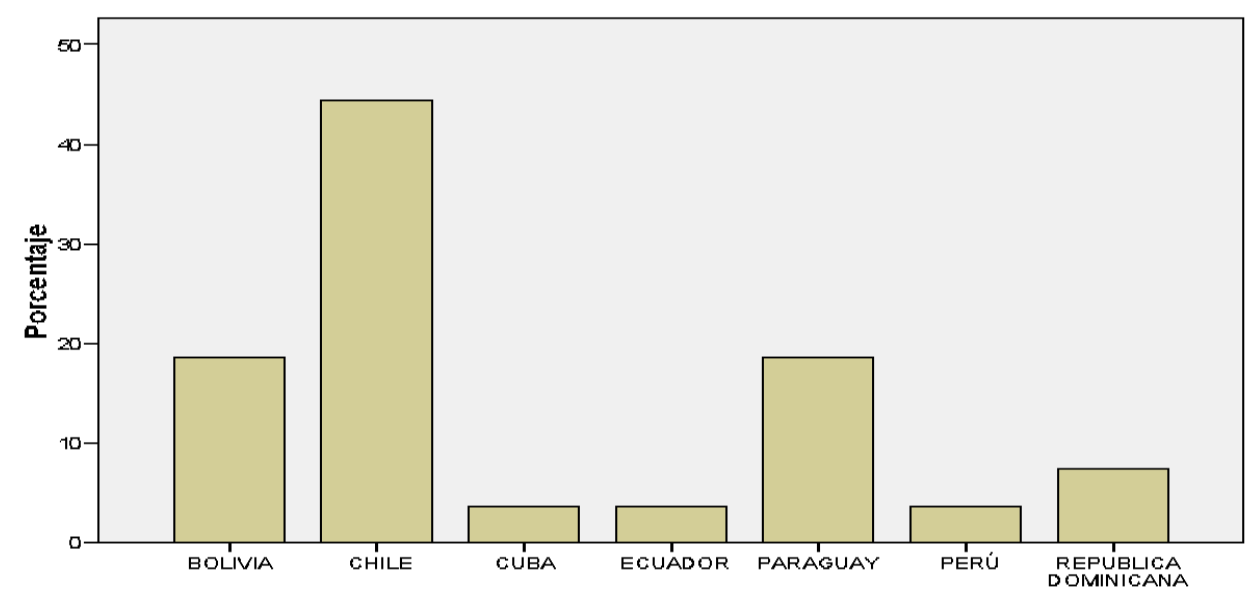

Fig. 4. Nacionalidad de estudiantes extranjeros en la UNPA-UARG. Fuente: Elaboración propia.

En relación a los niveles de estudios alcanzados, la mayoría de los encuestados ha manifestado tener el secundario completo, pero el nivel superior incompleto, debido al proceso de formación en curso, con porcentajes de nivel superior completo de $14,8 \%$ y nivel superior incompleto de $85,2 \%$ (Tabla 1 ). 


\begin{tabular}{lc}
\hline \multicolumn{1}{c}{ Nivel de Estudios } & $\begin{array}{c}\text { Porcentaje } \\
\mathbf{\%}\end{array}$ \\
\hline Superior completo & 14,8 \\
Superior incompleto & 85,2 \\
\hline Total & 100 \\
\hline
\end{tabular}

Tabla 1. Nivel de estudios alcanzados por los estudiantes extranjeros en la UNPA-UARG. Fuente: Elaboración propia.

Por último, el estado civil de los mismos se manifiesta de la siguiente forma: casada 11,1\%; casado $3,7 \%$; concubinato $14,8 \%$; divorciado $3,7 \%$; soltera $44,4 \%$ y soltero $22,2 \%$ (Fig. 5).

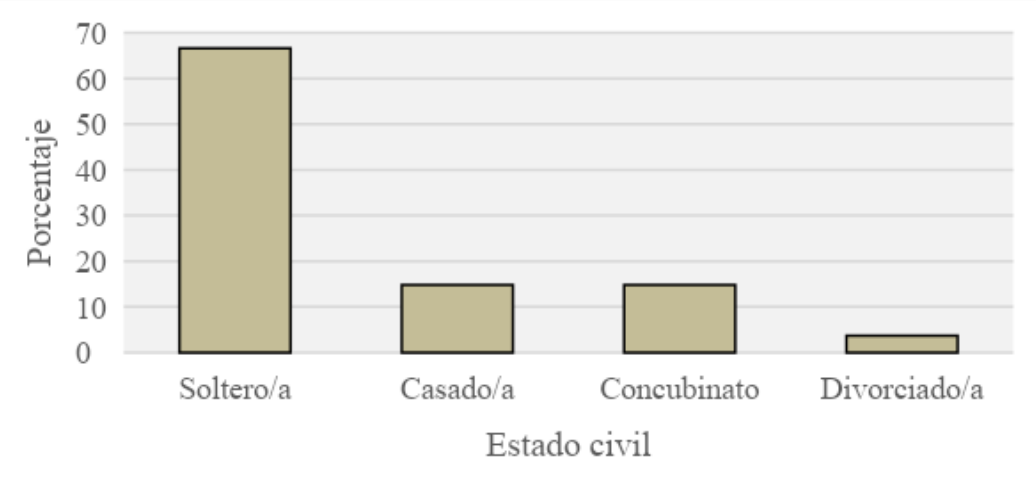

Fig. 5. Estado Civil de los estudiantes extranjeros en la UNPA-UARG. Fuente: Elaboración propia.

Ahora bien, se procederá a exponer los resultados correspondientes al eje de residencia en la ciudad de Río Gallegos, en el cual se indagó sobre los años de residencia, el barrio donde viven, si conviven con familiares, cuáles han sido los factores que incidieron para asentarse en el país y luego en la ciudad, como así también, si se encuentran a gusto viviendo en Río Gallegos y, finalmente, si vivirían el resto de su vida en la misma.

De acuerdo a los años de residencia, se observa que hay un mayor porcentaje en los estudiantes que se han asentado entre los años 2005 y 2011, representando un $11,1 \%$, siendo el resto de los años cifras inferiores que oscilan entre un 7,4\% en los años 2004, 2008, 2010, 2014 y 2015 (Fig. 6). 


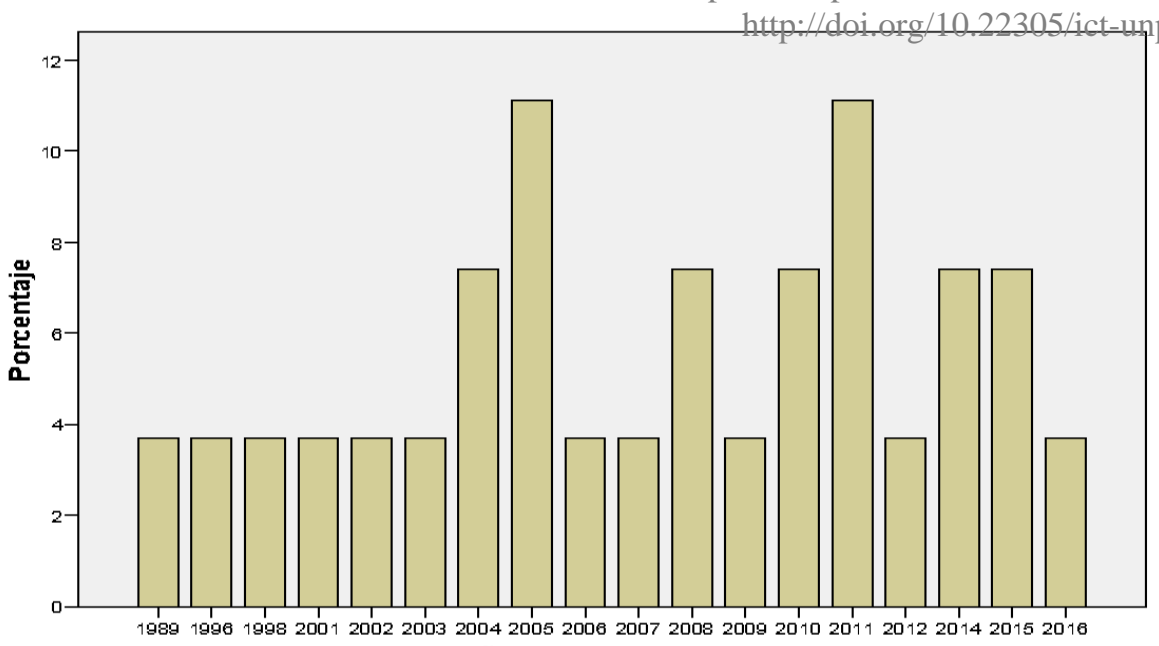

Fig. 6. Años de arribo a la ciudad de Río Gallegos de estudiantes extranjeros en la UNPA-UARG. Fuente: Elaboración propia.

En lo que respecta a los barrios donde residen los estudiantes extranjeros (Fig. 7), se observa que hay un mayor porcentaje en el barrio Belgrano (18,5\%). Cabe aclarar que muchos de los encuestados han manifestado no conocer el nombre de los barrios donde se encuentran viviendo, por lo que se lo ha representado con no sabe y/o no contesta (NS/NC) representado por un 14,8\%. Mientras que los barrios como: barrio 240, 499, El Puerto, Bicentenario I, San Benito representan cada uno un 7,4\% y los restantes representan sólo 3,7\%.

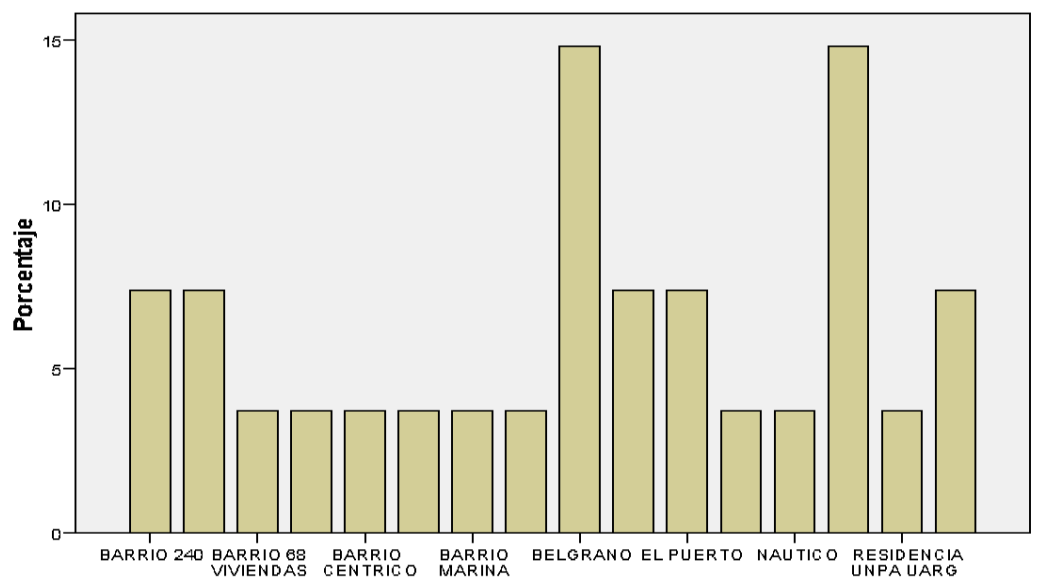

Fig. 7. Barrio donde residen los estudiantes extranjeros en la UNPA-UARG. Fuente: Elaboración propia.

Por otra parte, al ser consultados por si residen con familiares un 92,6\% ha expuesto que sí, mientras que sólo el 7,4\% ha respondido que no (Tabla 2).

\begin{tabular}{lc}
\hline Residen con familiares & $\begin{array}{c}\text { Porcentaje } \\
\%\end{array}$ \\
\hline SI & 92,60 \\
NO & 7,4 \\
\hline
\end{tabular}

Tabla 2. Convive con familiares. Fuente: Elaboración propia.

A continuación, se detallan los factores que han impulsado a los estudiantes a salir de su país en primera instancia, y luego, aquellos factores que incidieron en la elección de asentarse en 
la ciudad de Río Gallegos. Cabe destacar que en ambas preguntas se daba la posibilidad de elegir más de una opción de acuerdo a la realidad y vivencia de cada estudiante.

Con respecto a lo primero, los mismos han expuesto factores como: educativos 11,1\%; familiares 37,0 \%; familiares y laborales 3,7\%; laborales 40,7\%; otros (paseo) 3,7\%; otros (vacaciones) $3,7 \%$ (Fig. 8).

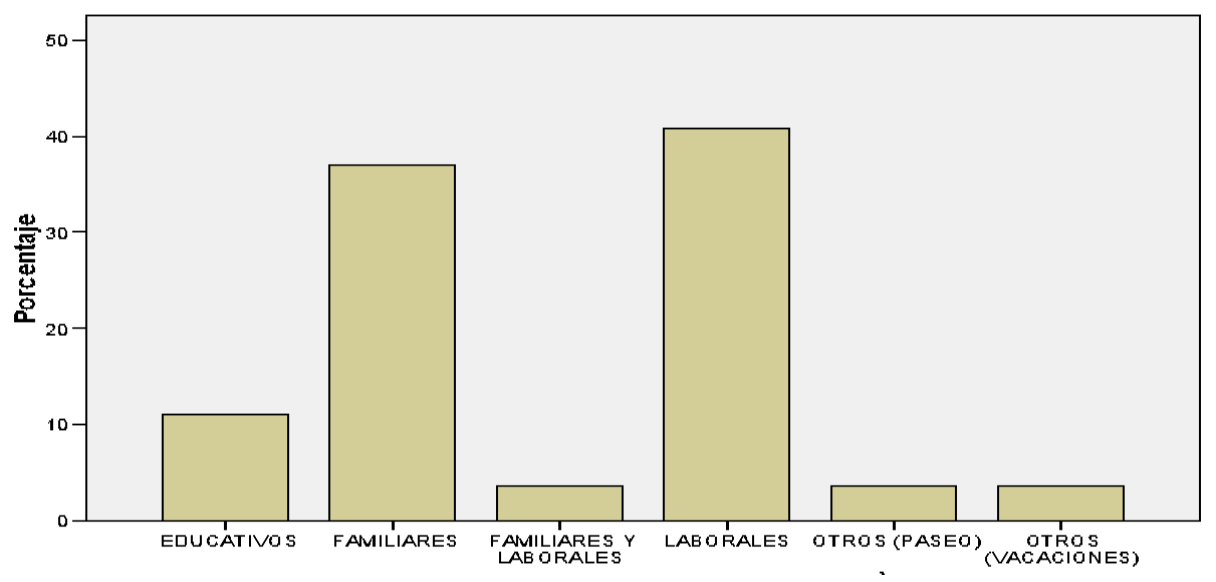

Fig. 8. Factores para salir de su país. Fuente: Elaboración propia.

Por otro lado, aquellos factores que impulsaron la residencia de los mismos en la ciudad, han sido: laborales $63,0 \%$; familiares $25,9 \%$ y educativos $11,1 \%$ (Fig. 9).

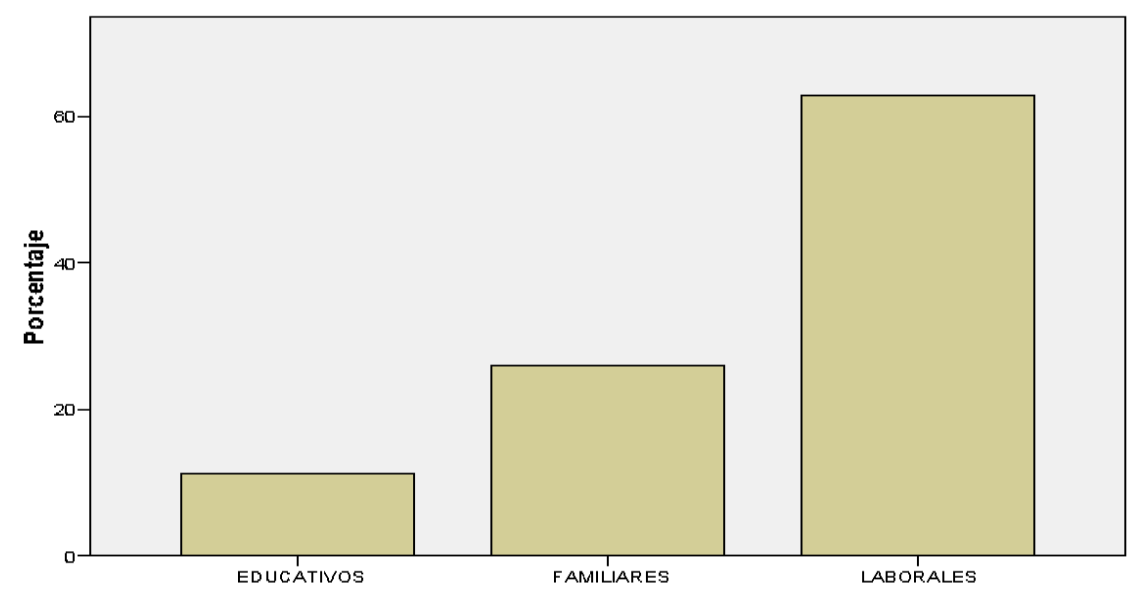

Fig. 9. Factores para asentarse en Río Gallegos. Fuente: Elaboración propia.

Asimismo, todos los estudiantes encuestados han manifestado en una totalidad del $100 \%$ que se sienten a gusto viviendo en la ciudad, pero al ser consultado si viviría el resto de su vida en la misma un $74,1 \%$ ha respondido que sí, mientras que el $25,9 \%$ restante respondió que no (Fig. 10).

De acuerdo a la pregunta de por qué, los primeros han manifestado su conformidad en cuanto las condiciones de vida que les proporciona la ciudad, la calidad de los servicios públicos tales como salud, educación, justicia, entre otros. Mientras que los que han respondido que no se puede inferir a que los mismos se han desarrollado parte de su infancia-adolescencia en el país de origen y que los motivos de su traslado y permanencia en la ciudad no ha sido por una decisión a voluntad, sino por motivos netamente familiares. 


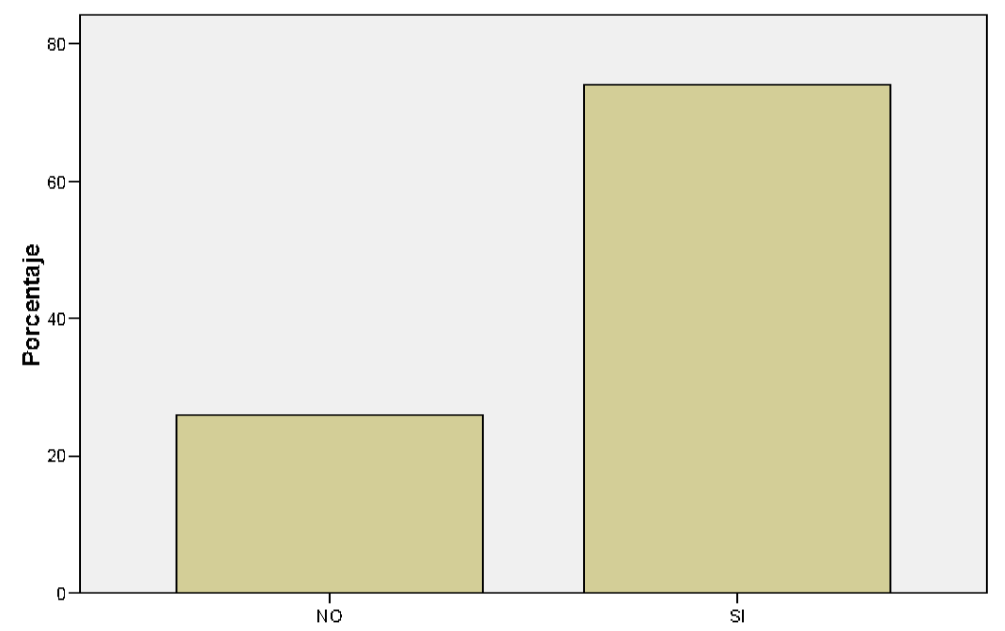

Fig. 10. Viviría el resto de su vida en Río Gallegos. Fuente: Elaboración propia.

Prosiguiendo con el análisis y de acuerdo con el eje tres, vida académica, se detallarán los resultados en base a: carrera de grado, año de ingreso a la universidad y a la carrera, motivos por los que ha elegido la UNPA-UARG para llevar adelante sus estudios, si pertenece a un grupo de estudio, si el mismo se encuentra compuesto por estudiantes extranjeros, cuántos conoce en caso que así fuera, si se relaciona por fuera del ámbito universitario con los mismos y por último, si consideran que la UNPA-UARG promueve el intercambio cultural entre sus estudiantes.

En las carreras de grado (Fig. 11), se observa que hay una gran cantidad de inscriptos extranjeros en Licenciatura en Enfermería con un 25,9\%, Ingeniería en Recursos Naturales Renovables (IRNR), Ingeniería Química y Licenciatura en Psicopedagogía representan cada una un $11,1 \%$ de inscriptos. Luego se encuentra Licenciatura en Administración y Licenciatura que cada una representa un $7,4 \%$, quedando en menor porcentaje carreras como Licenciatura en Trabajo Social, Tecnicatura Universitaria en Acompañamiento Terapéutico (TUAT), Licenciatura/Tecnicatura en Turismo, Profesorado en Letras, Profesorado en Historia y Profesorado en Matemática con 3,7\% cada una.

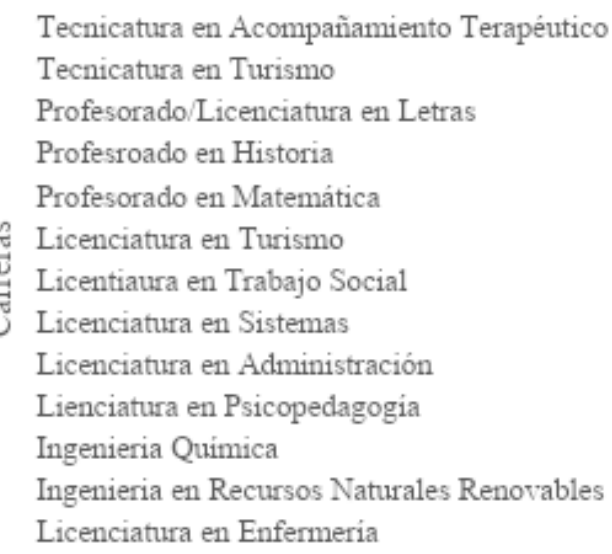

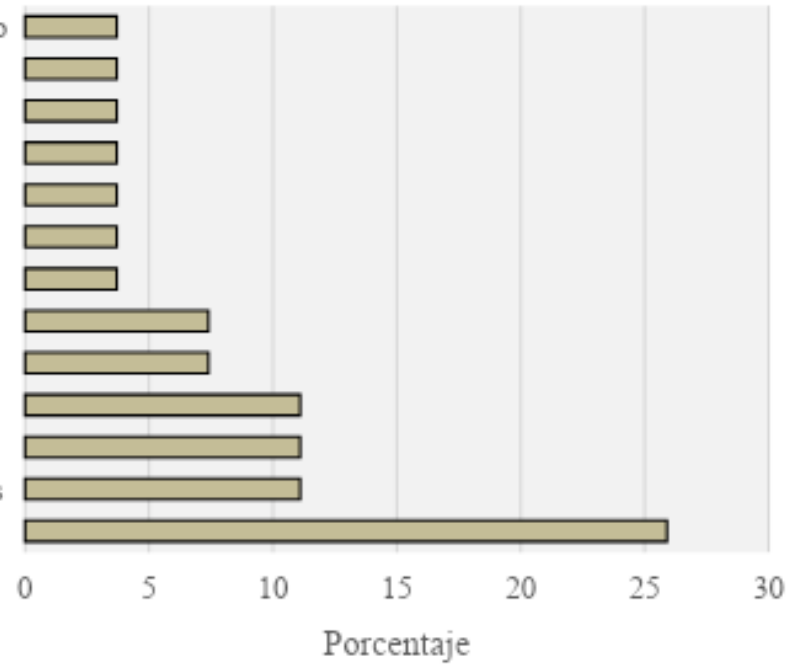

Porcentaje

Fig. 11. Carreras de grado. Fuente: Elaboración propia. 
Respecto al año de ingreso a la universidad, se obtuvo como resultado que existe un gran número de inscriptos entre el año 2018 y 2019, siendo en menor porcentaje los años anteriores a esta franja (Fig. 12).

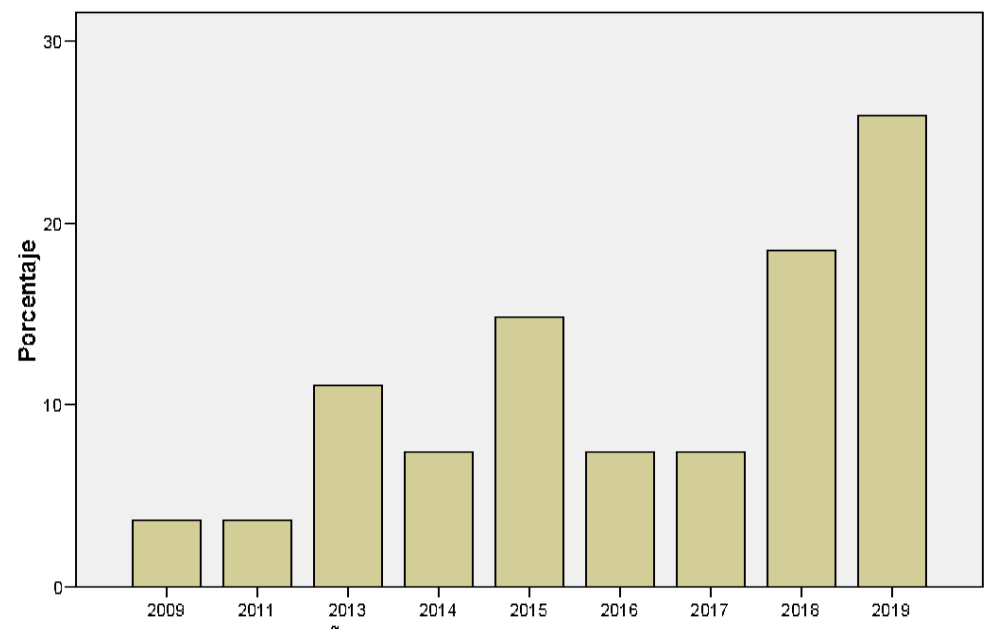

Fig. 12. Año de ingreso a la UNPA-UARG. Fuente: Elaboración propia.

En relación a los factores que incidieron en la elección de los estudiantes para formarse en la UNPA-UARG, se destacan los siguientes resultados, haciendo la salvedad que se les ha dado la posibilidad de elegir más de una opción, por lo que a continuación se procederá a detallar cada resultado correspondiente al gráfico: oferta académica 14,8\%; oferta académica/pública y gratuita $7,4 \%$; oferta académica/horarios de cursada 3,7\%; oferta académica/ubicación $3,7 \%$; oferta académica/pública y gratuita $22,2 \%$; oferta académica/sistema de becas/pública y gratuita $3,7 \%$; pública y gratuita $3,7 \%$; pública y gratuita $29,6 \%$; pública y gratuita/horario de cursada 7,4\%; pública y gratuita/sistema de becas 3,7\% (Fig. 13).

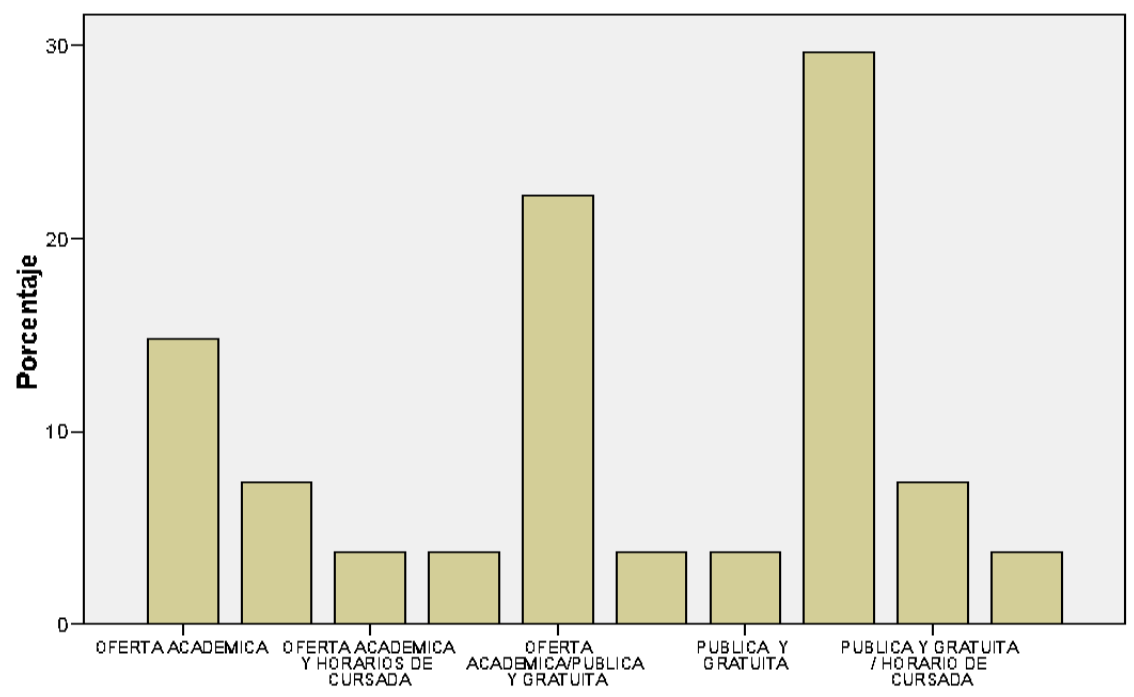

Fig. 13. Elección de UNPA-UARG para estudios superiores. Fuente: Elaboración propia

Al consultar acerca de si pertenecen a un grupo de estudio en sus respectivas carreras de grado el $70,4 \%$ ha respondido que sí, mientras que el $29,6 \%$ ha respondido que no. Igualmente al indagar acerca de la conformación de dichos grupos, es decir, si los mismos se encontraban compuesto por estudiantes extranjeros, el $100 \%$ de los encuestados expuso que 
no, debido a que se relacionaban con estudiantes argentinos. Por otro lado, se pudo evidenciar que las actividades dentro del ámbito universitario que más comparten los estudiantes encuestados son el cursado de las diversas asignaturas y en la resolución de trabajos prácticos grupales.

Ahora bien, en lo que respecta a si estos estudiantes tienen conocimiento de otros estudiantes extranjeros formándose en la misma casa de altos estudios, el 59,3\% expuso que no, mientras que un $40,7 \%$ si tiene conocimiento. Cabe aclarar, que se les ha consultado en número cuántos estudiantes extranjeros conocían, lo cual se puede apreciar en la Fig. 14.

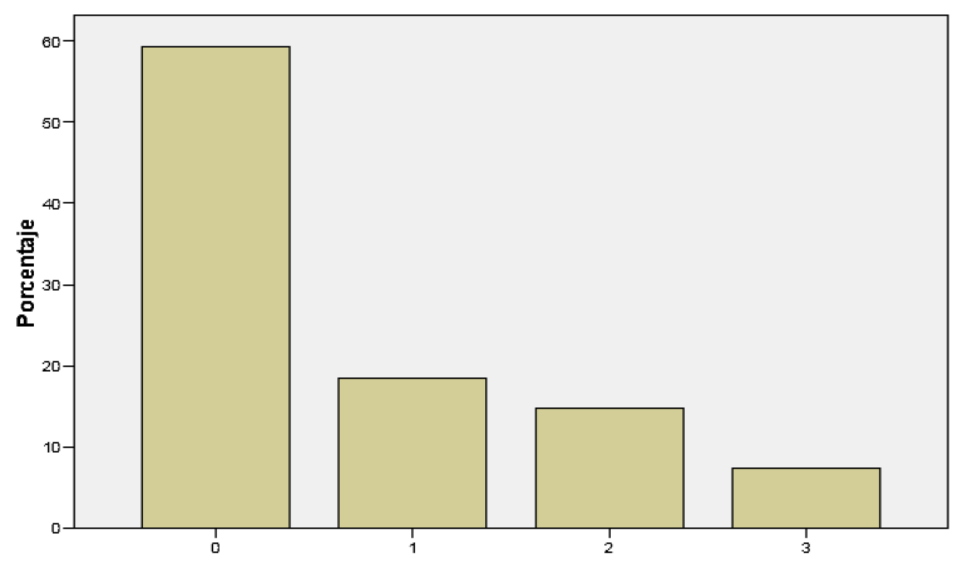

Fig. 14. Cantidad de estudiantes extranjeros que conocen en la UNPA-UARG. Fuente: Elaboración propia

Ante la pregunta de si estos estudiantes tenían conocimiento de estudiantes de su misma nacionalidad realizando una carrera de grado dentro de la UNPA-UARG, un 51,9\% respondió que sí y sólo el 48,1\% respondió que no. Cabe aclarar, que se les ha consultado en número cuántos estudiantes extranjeros conocían, expresado en la Fig. 15.

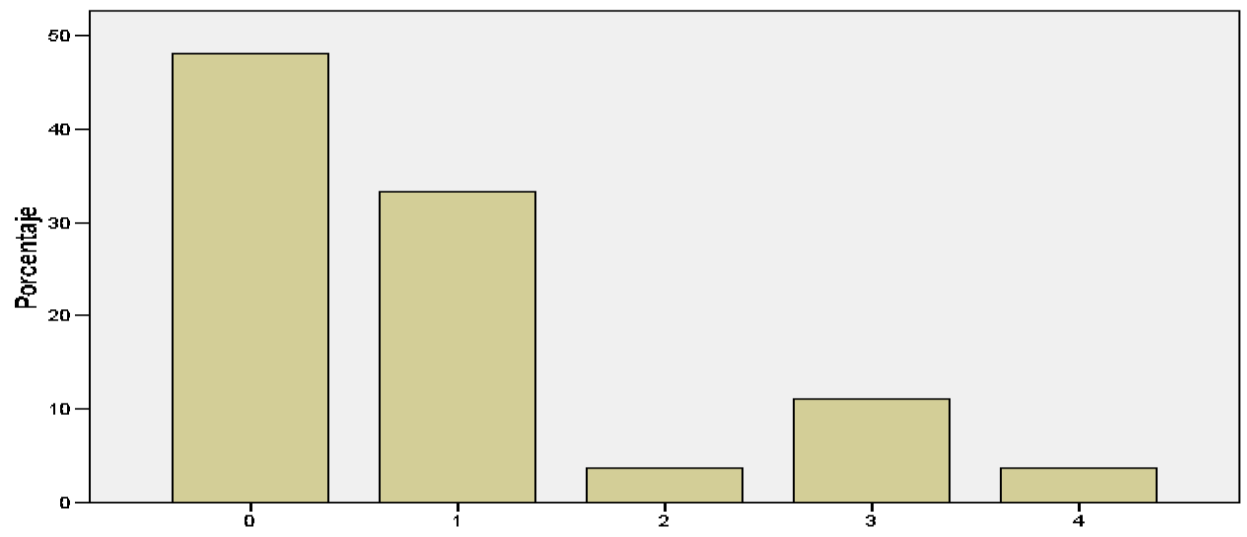

Fig. 15. Cantidad de estudiantes extranjeros de su misma nacionalidad que conocen en la UNPAUARG. Fuente: Elaboración propia.

En base a si estos se relacionan con dichos estudiantes por dentro del ámbito de la UNPAUARG (Tabla 3), un 63,0\% contestó que no, mientras que el 37,0\% contestó que sí. Ahora bien, al ser consultados si se reúnen y/o relacionan por fuera del ámbito universitario, un 
55,6\% respondió que no y solo un 44,4\% respondió que sí (Tabla 4). Esto denota que el tener conocimiento de más estudiantes no asegura la relación entre los mismos.

\begin{tabular}{lc}
\hline $\begin{array}{c}\text { Se relaciona con estudiantes } \\
\text { extranjeros en la UNPA }\end{array}$ & $\begin{array}{c}\text { Porcentaje } \\
\%\end{array}$ \\
\hline NO & 55,6 \\
SI & 44,4 \\
\hline
\end{tabular}

Tabla 3: Se relacionan con otros estudiantes extranjeros en el ámbito de la UNPA-UARG. Fuente: Elaboración propia.

\begin{tabular}{lc}
\hline Se relaciona con estudiantes & $\begin{array}{c}\text { Porcentaje } \\
\%\end{array}$ \\
extranjeros fuera de la UNPA & 55,6 \\
\hline NO & 44,4 \\
SI & \\
\hline
\end{tabular}

Tabla 4: Se relacionan con otros estudiantes extranjeros por fuera del ámbito universitario. Fuente: Elaboración propia.

Por último, para concluir con los resultados del mencionado eje, se les ha preguntado a los encuestados si la UNPA UARG genera espacios de intercambio cultural de los estudiantes extranjeros, dando la posibilidad de detallar qué actividades, en caso de respuesta afirmativa. En base a ello el 88,9\% respondió que no, el 7,4\% respondió que sí y sólo el 3,7\% no sabían o no contestaron (NS/NC) (Fig. 16). Aquellos que respondieron afirmativamente, manifestaron participar de jornadas recreativas musicales, como así también de Proyectos de Investigación y Agrupaciones Juveniles en la Universidad.

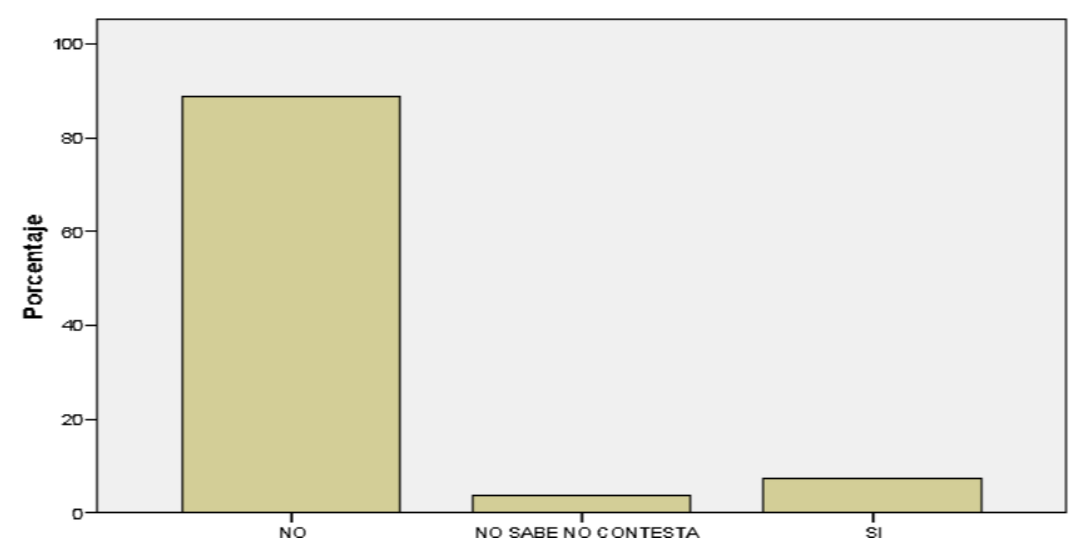

Fig. 16. La UNPA-UARG genera espacios de intercambio cultural. Fuente: Elaboración propia.

El último y cuarto eje de la encuesta refiere a lugares de intercambio social y cultural en la ciudad, donde se dejará plasmados los resultados a si estos estudiantes extranjeros tienen contacto con personas de su misma nacionalidad dentro de la ciudad, si tienen espacios de encuentro, si conocen agrupaciones y/o asociaciones de su misma nacionalidad y si tiene participación en las mismas, como así también, si conoce de festividades típicas de su país en la ciudad, si participa de ellas. Luego, si realiza prácticas relacionadas a la cultura y costumbres propias de su lugar de origen, indagan donde las desarrolla en caso de ser afirmativa, entre otras. 
De acuerdo a que si los estudiantes extranjeros tienen contacto con personas de su misma nacionalidad dentro de la ciudad de Río Gallegos el 81,5\% respondió que sí, mientras que el 18,5\% respondió que no (Fig. 17).

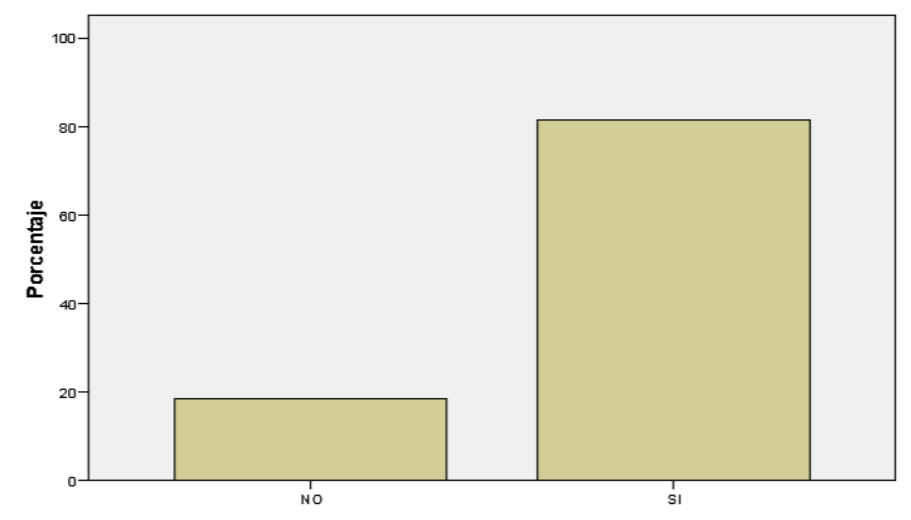

Fig. 17: Contacto con personas de su nacionalidad en Río Gallegos. Fuente: Elaboración propia

Ahora bien, el 55,6\% ha manifestado tener un lugar de encuentro con personas de su misma nacionalidad y sólo el 44,4\% manifestó que no (Fig. 18). Sin embargo, al ser consultado sobre el punto de dichos encuentros, quienes han respondido afirmativamente referenciaron a sus domicilios, no espacios públicos en la ciudad, lo que demuestra que no poseen un espacio definido para sus encuentros. Por otro lado, los que respondieron que no se reunen con personas de su misma nacionalidad agregaron la categoría "ningún lugar", para dejar en claro que no existen encuentros, por este motivo se refleja en el gráfico la presencia de esa variable. (Fig. 19)

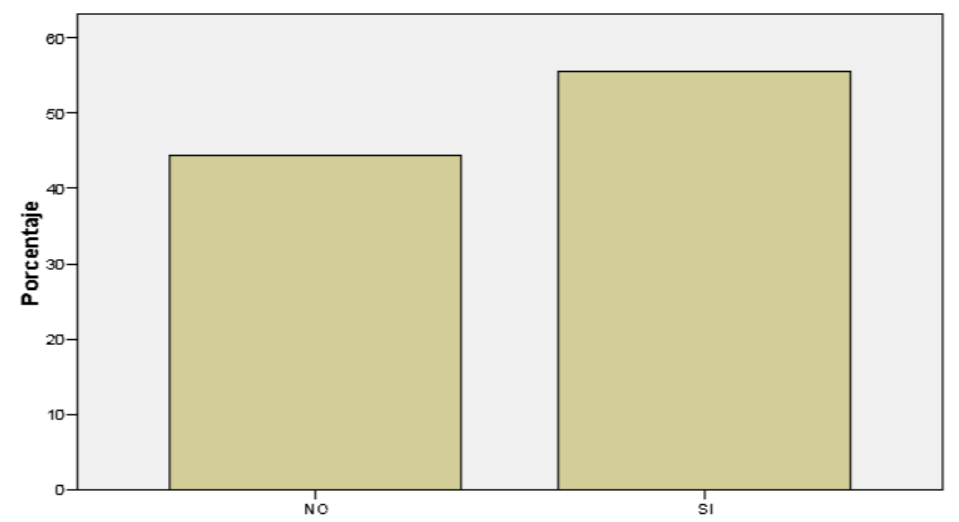

Fig. 18. Contacto para reunirse con personas de su misma nacionalidad. Fuente: Elaboración propia 


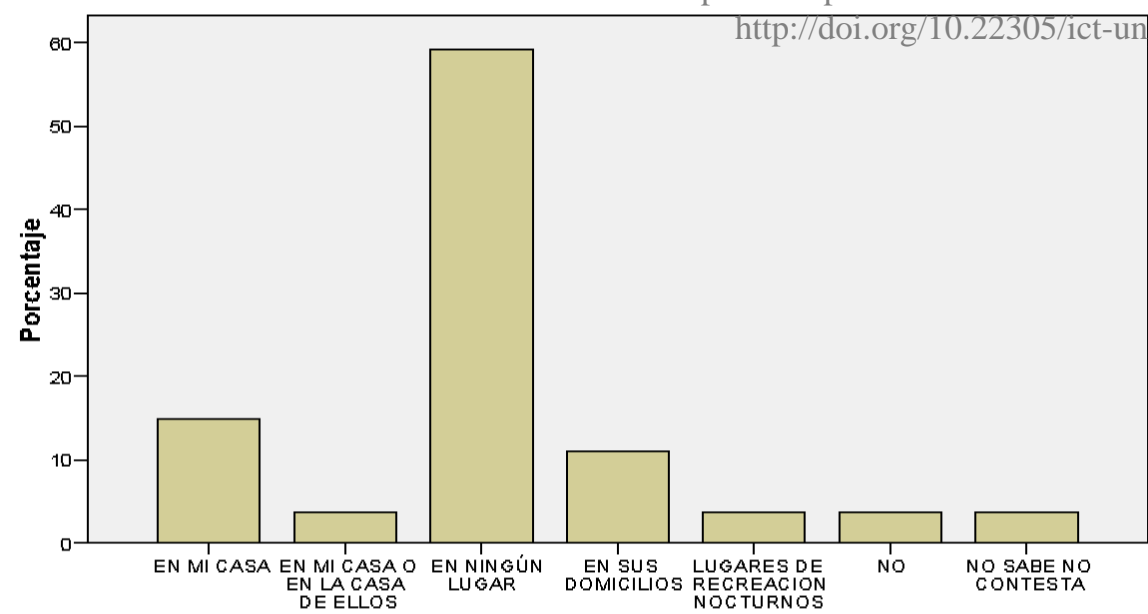

Fig. 19. Lugares para reunirse con personas de su misma nacionalidad. Fuente: Elaboración propia.

Con lo que respecta a si estos estudiantes conocen agrupaciones y/o asociaciones de su misma nacionalidad, donde el 55,6\% ha respondido que no y el 44,4\% respondió que sí (Tabla 5). Ahora bien, de acuerdo a si participan en ellas el 96,3\% respondió que no y sólo el 3,7\% sí (Tabla 6).

\begin{tabular}{lcc}
\hline Conocimiento de agrupaciones & y/o & $\begin{array}{c}\text { Porcentaje } \\
\%\end{array}$ \\
asociaciones de su misma nacionalidad & & 55,6 \\
NO & & 44,4 \\
SI
\end{tabular}

Tabla 5. Conocimiento de agrupaciones y/o asociaciones de su misma nacionalidad. Fuente: Elaboración propia.

\begin{tabular}{|c|c|}
\hline $\begin{array}{l}\text { Participación en dichas agrupaciones y/o } \\
\text { asociaciones }\end{array}$ & $\begin{array}{c}\text { Porcentaje } \\
\%\end{array}$ \\
\hline NO & 96,3 \\
\hline SI & 3,7 \\
\hline
\end{tabular}

Tabla 6. Participación en dichas agrupaciones y/o asociaciones. Fuente: Elaboración propia.

En base a los lugares donde se reúnen y llevan a cabo actividades desde las agrupaciones, principalmente, los estudiantes de nacionalidad chilena han expuesto como lugar referencial el Centro de Residentes Chilenos en Río Gallegos, el cual funciona en el centro de la ciudad y el cual organiza diversas actividades para los residentes chilenos y tiene alta representatividad en la comunidad, por ser el Centro que nuclea a los inmigrantes que mayor presencia -en cantidad y tiempo- tienen en la ciudad. También se referenció como lugar de encuentro a El Canelo, el cual es un local bailable ubicado en el barrio Belgrano, habitado en su mayoria por población de origen chileno. En este lugar de esparcimiento se baila musica del país vecino y se comparten comidas tipicas del mismo, sobre todo en el mes de septiembre, para los festejos de la independencia de Chile.

Es importante aclarar que sólo se encuentran representados en la ciudad a través de asociaciones de inmigrantes, además de la chilena, la nacionalidad boliviana, con dos centros de residentes: Virgen de Urkupiña y 6 de Agosto, pero que no fueron referenciados por los encuestados.

Por otro lado, algunos encuestados mencionaron el Obispado como lugar de encuentro, en virtud que en esa institución funciona la Pastoral Migratoria, la cual realiza un fuerte e 
importante trabajo relacionado con la orientación en tramites migratorios, entre otras actividades.

Siguiendo bajo esta misma línea, al indagar si tenían conocimiento de festividades típicas de su país que se celebren en la ciudad el 59,3\% expuso que sí, mientras que el 40,7\% manifestó que no (Fig. 20). Respecot al lugar donde las llevan a cabo, surge de los estudiantes chilenos lugares como el Centro Chileno y El Canelo. Cabe aclarar que aquellos encuestados que manifestaron no conocer sobre festividades típicas de su país, referenciaron la categoría "ningún lugar". (Fig. 21). Prosiguiendo, se les ha consultado si participaban en estas en caso de responder de manera afirmativa donde el 81,5\% manifestó que no y sólo el 18,5\% sí.

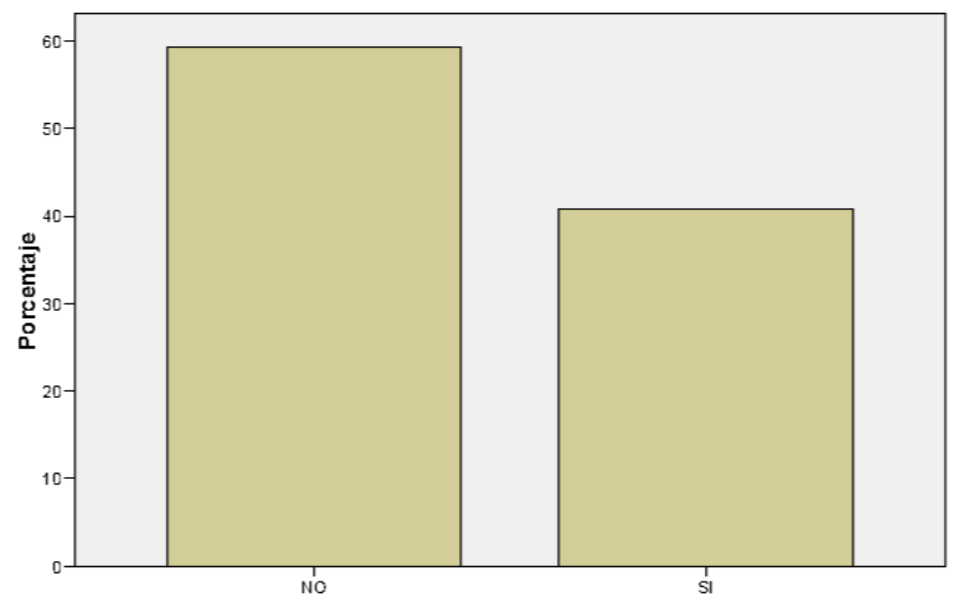

Fig. 20. Celebraciones típicas en Río Gallegos. Fuente: Elaboración propia.

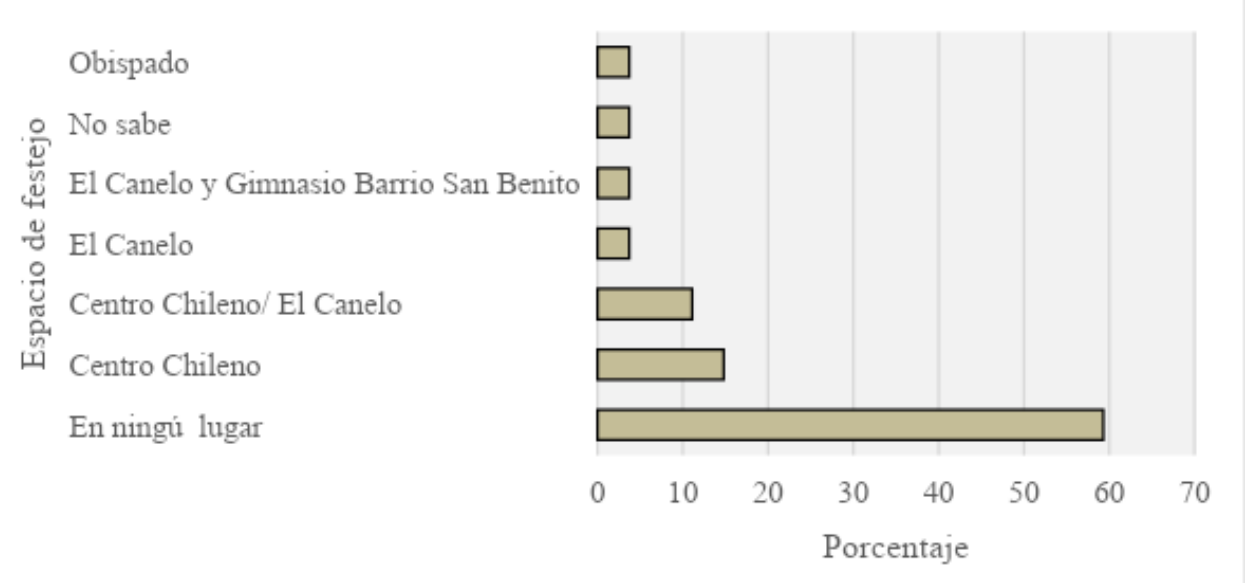

Fig. 21. Lugares donde se llevan a cabo celebraciones típicas en Río Gallegos. Fuente: Elaboración propia.

Por otra parte, en los resultados que corresponden a si los mismos realizan prácticas culturales relacionadas con las costumbres de su país de origen, un $81,5 \%$ respondió que no y sólo un 18,5\% respondió que sí (Tabla 7), al indagar acerca de cuáles son dichas costumbres (Fig. 22) los que han respondido de forma afirmativa, destacaron que realizaban comidas típicas. Respecto al lugar en los que realizan estas prácticas, un gran porcentaje, conincidente con aquellos que respondieron que no realizan estas prácticas, referenciaron "ningún lugar". 
Aquellos que si realizan estas prácticas, referencian los domicilios particulares como espacio principal. (Fig. 23).

\begin{tabular}{lc}
\hline Realiza prácticas culturales de su nacionalidad & $\begin{array}{c}\text { Porcentaje } \\
\%\end{array}$ \\
\hline SI & 81,5 \\
NO & 18,5 \\
\hline
\end{tabular}

Tabla 7. Prácticas culturales relacionadas a su lugar de origen. Fuente: Elaboración propia

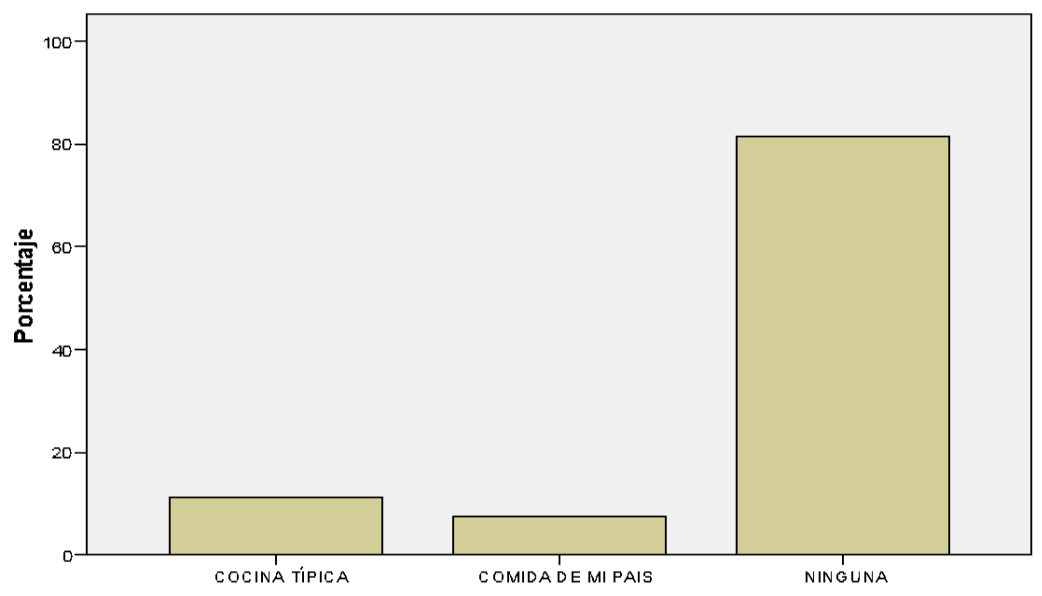

Fig. 22. Práctica cultural relacionada a las costumbres del país de origen. Fuente: Elaboración propia.

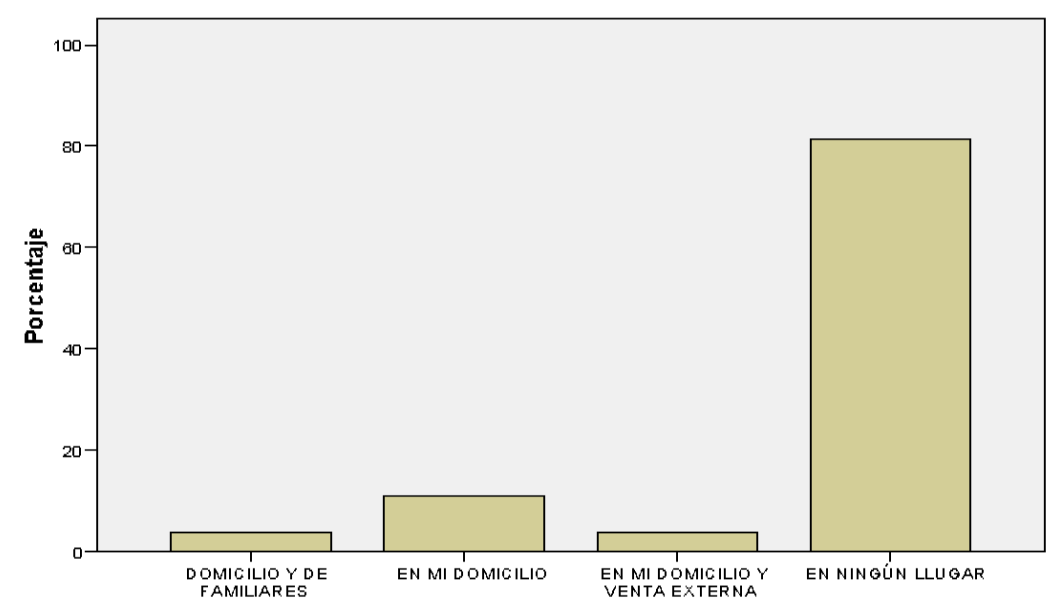

Fig. 23. Lugares donde desarrollan prácticas culturales relacionadas a las costumbres del país de origen. Fuente: Elaboración propia.

Ahora bien, al indagar acerca de con qué frecuencia puede llevar a cabo sus prácticas culturales en la ciudad de Río Gallegos donde el 74,1\% expuso que nunca, mientras que el 25,9\% expuso pocas veces. (Fig. 24) 


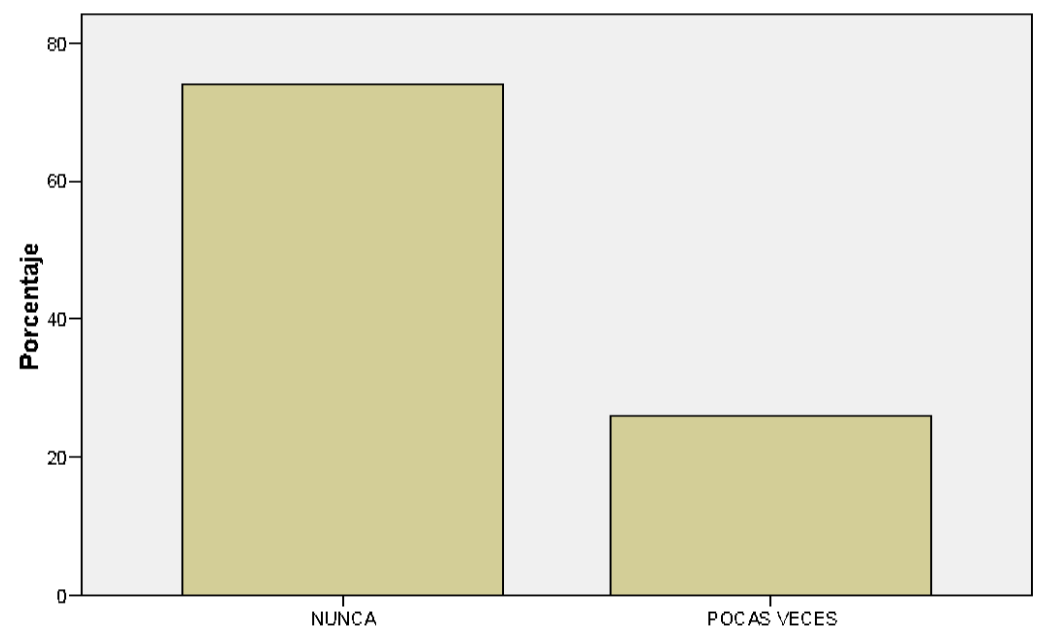

Fig. 24. Frecuencia con la que lleva a cabo sus prácticas culturales en Río Gallegos.

Fuente: Elaboración propia.

Respecto a los lugares donde pueden llevar a cabo prácticas culturales con personas de su misma nacionalidad, un gran porcentaje indica "ningún lugar", haciendo referencia a que no llevan adelante estas prácticas, o bien, no poseen un espacio concreto. Por otro lado, se destacan las respuestas de los estudiantes de nacionalidad chilena, los cuales señalaron el Centro Chileno y El Canelo. Las otras respuestas obtenidas mencionan sus hogares y un porcentaje menor en espacios de la UNPA-UARG (sin especificar en detalle). (Fig. 25).

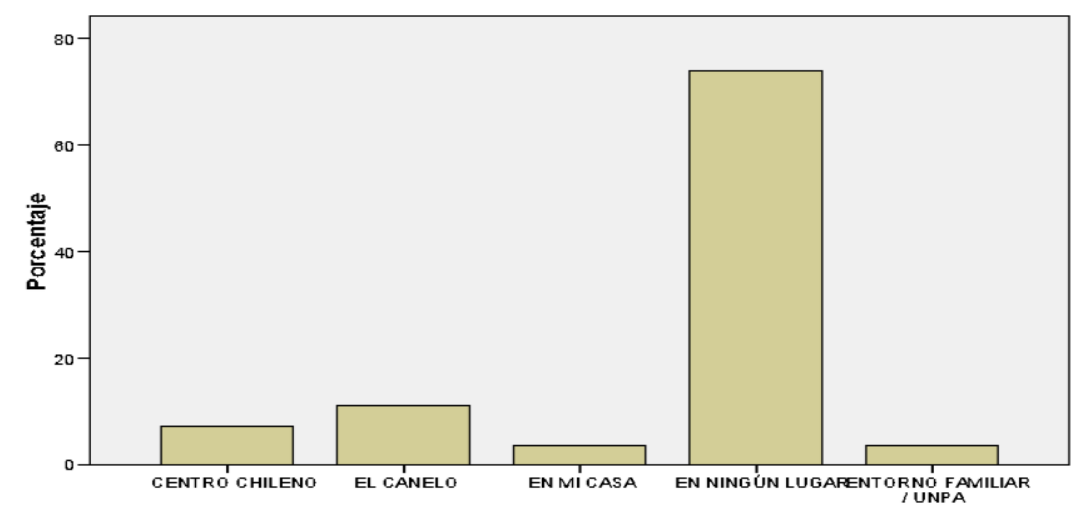

Fig. 25. Lugares donde pueden llevar adelante sus prácticas culturales con frecuencia. Fuente: Elaboración propia.

Las últimas preguntas de la encuesta se encontraron direccionadas a relevar si estos estudiantes se sientes representados por el colectivo migrante de su misma nacionalidad en la ciudad de Río Gallegos, entendiendo a la representación en términos de reflejar fielmente las costumbres y pautas culturales del colectivo migrante de la misma nacionalidad y, por sobre todo, experimentar el sentido de pertenencia para con este grupo. Respecto a ello, el $74,1 \%$ ha respondido que sí se siente representado y parte del mismo, mientras que sólo el 25,9\% respondió que no (Fig.26).

Ahora bien, al consultar acerca del por qué de ambas respuestas, aquellos que respondieron afirmativamente señalan que los une la cultura y las costumbres, siendo lo más significativo a ello la comida típica y el lenguaje. En contraposición, quienes han manifestado que no se sienten representados, señalaron como razón el simple hecho de no conocer personas de su misma nacionalidad, tanto en la ciudad como en el campus universitario de la UNPA UARG. 


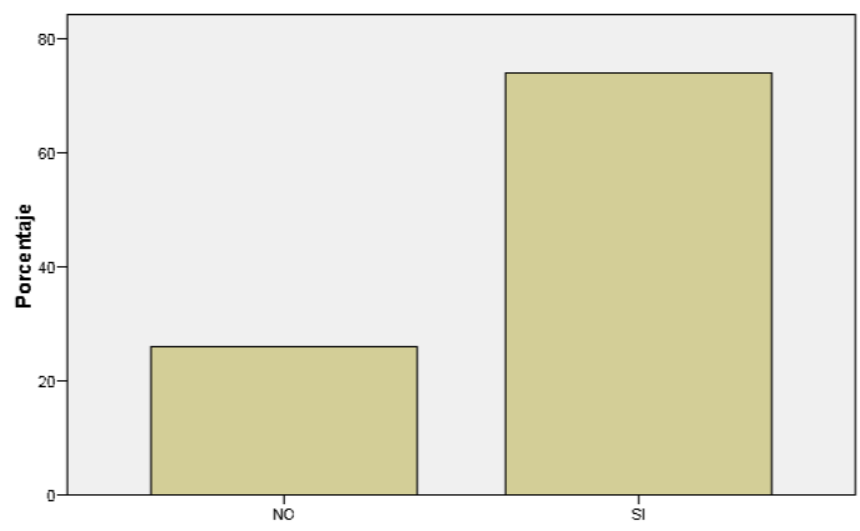

Fig. 26. Representación del colectivo de migrantes de su misma nacionalidad. Fuente: Elaboración propia.

Por último, al consultar si se sienten representados por los estudiantes migrantes de su misma nacionalidad dentro de la UNPA-UARG, el 55,5\% ha manifestado que no, mientras que el 44,4\% manifestó que sí (Fig. 27). La explicación a ello ha sido en primera instancia que los mismos no se conocen entre sí o más allá de conocerse no tienen contacto fluido.

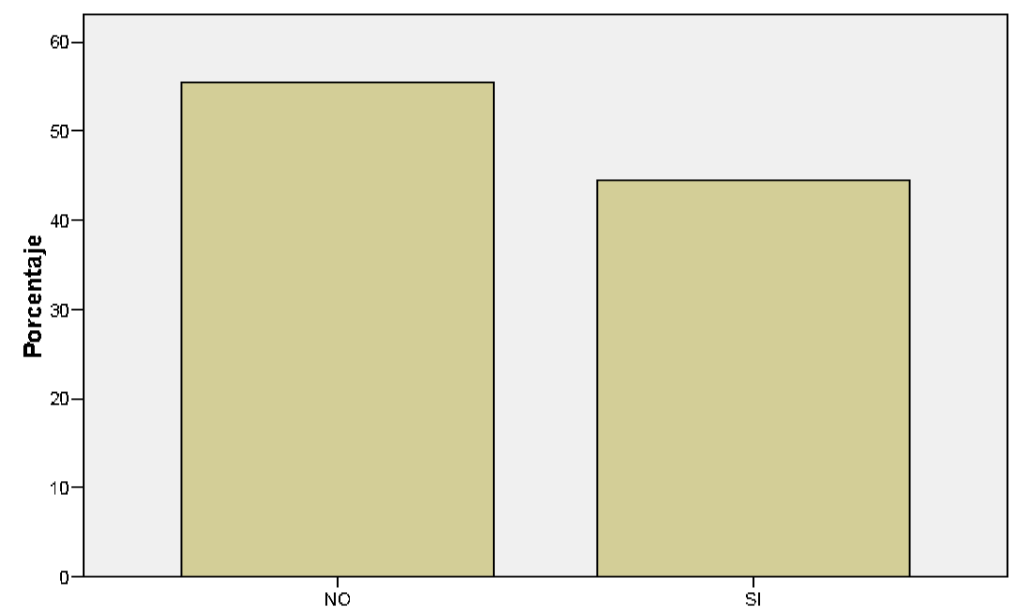

Fig. 27. Representación de los estudiantes migrantes de su misma nacionalidad.

Fuente: Elaboración propia.

\subsection{Análisis y discusión}

A partir de los resultados obtenidos en las encuestas se puede afirmar que la mayoría de los estudiantes extranjeros de la UNPA-UARG no tiene relación y/o conocimiento de otros estudiantes de su misma nacionalidad u otras. Esto denota que los mismos solo se remiten al contacto y vinculación con estudiantes argentinos por medio de las diversas cursadas de asignaturas y de las actividades obligatorias de las mismas que requieren trabajo grupal.

Se observa también que hay una gran cantidad de estudiantes extranjeros que han elegido la carrera de Licenciatura en Enfermería, seguido por las Ingenierías tanto en Recursos Naturales Renovables y Química. La lectura que se puede realizar en base a ello es que existe 
una gran demanda de profesionales correspondientes a dichos campos, por lo cual podría ser un facilitador en la inserción laboral.

Respecto a la universidad, los estudiantes han manifestado que ésta no tiene una acción y/o política concreta que potencie el intercambio por medio de actividades o espacios marcados para el intercambio social y cultural, lo cual dificulta la apropiación del espacio en este sentido.

Por otra parte, de acuerdo a los resultados de cómo se sienten viviendo en la ciudad de Río Gallegos, la mayoría ha manifestado que está a gusto debido a los beneficios laborales y servicios públicos que esta ofrece por medio de salud, educación, entre otros. Sin embargo, se pudo observar que éstos no consideran que la ciudad tenga espacios que los identifique como migrantes, es decir, espacios donde se genere efectivamente un intercambio cultural entre sujetos de una misma nacionalidad. Por lo que aquí cabe preguntarse qué políticas culturales se encuentran en vigencia e implementan las instituciones y organizaciones que se dedican a ello y como son aplicadas para hacer visible a las colectividades.

Por último, es relevante destacar que los estudiantes en su mayoría no tienen conocimiento de agrupaciones y/o asociaciones que reivindiquen la cultura de su país de origen, exceptuando aquellos estudiantes de nacionalidad chilena que han destacado como lugares referenciales el Centro Chileno y El Canelo, siendo éstos utilizados para dar a conocer de forma permanente sus costumbres y/o tradiciones. Esto permite repensar cómo son los vínculos entre la población migrante y el accionar de las instituciones que se abocan a ellos, ya sea de entidades nacionales como provinciales, y cuán importante es la visión de lo diverso en materia migratoria.

\section{Conclusiones}

A modo de conclusión, se afirma que no existe un intercambio entre los estudiantes extranjeros, lo cual se constituye como un punto destacable en el sentido que no hay una motivación de replicar costumbres dentro o fuera del Campus de la UNPA UARG. Sin embargo, esto no significa que no exista una identidad territorial entendida como tal, sino que, como se ha particularizado, el análisis en una población migrante caracterizada por ser joven se puede inferir que con el paso del tiempo se van a ir consolidando cada vez más espacios y/o lugares que representen y sean significativos para las comunidades migrantes, que deberían ser potenciados y respaldados por medio de políticas de Estado de intercambio cultural.

\section{Recomendaciones}

Las recomendaciones que surgen de lo investigado se centran en que se tome posición dentro del ámbito universitario a la promoción e intercambio cultural entre estudiantes, sobre todo en los extranjeros, para enriquecer la diversidad de costumbres, tradiciones, lenguaje, entre otros. Esta situación generaría en la población estudiantil en general el apropiarse de los espacios y resignificarlos a través de diversas actividades o iniciativas.

Por otro lado, sería prioritario que las instituciones nacionales y provinciales evalúen aquellas políticas públicas y sociales vigentes en materia migratoria y cultural, debido a que es necesario problematizar por qué aún no se visualizan o utilizan espacios para el intercambio entre colectividades extranjeras, más allá de sus fechas conmemorativas, patrias y religiosas. 


\section{Bibliografía}

ABU-WARDA N. (2007). Las migraciones internacionales. Revista Ciencia de las Religiones, Universidad Complutense de Madrid, p. 33-50.

AMPUERO C. (2012). Evolución del índice de masculinidad en el departamento del Lago Argentino, Provincia de Santa Cruz, Patagonia Austral Argentina (1947-2010). GEOUSAL-Revista Científica de Geografía-Facultad de Historia, Geografía y Turismo de la Universidad del Salvador. Año VII N ${ }^{\circ}, 12$.

AMPUERO C., NORAMBUENA M., SEGOVIA STANOSS M. (2012). La impronta de la migración chilena durante el siglo XX en el Paisaje Urbano de la ciudad de Río Gallegos. Los barrios Belgrano y Nuestra Señora del Carmen como Paisaje Cultural Urbano. Paisajes culturales: memorias de las Jornadas de reflexión acerca de los paisajes culturales de Argentina y Chile, en especial los situados en la región Patagónica. UNPA. Río Gallegos CD-ROM. p. 163 - 180

AMPUERO C., NORAMBUENA M., SEGOVIA STANOSS M., CÁCERES A. P., MELGAREJO G., GONZÁLEZ C. (2019). La inmigración chilena en Río Gallegos, Santa Cruz, Argentina: su impronta territorial en los barrios Belgrano y Nuestra Señora del Carmen. UNPAEdita. Río Gallegos. (en prensa)

CÁCERES A. P., VISCIGLIA DE GOREZ E., VÁZQUEZ M. (1996). La Percepción Urbana de Río Gallegos. Anales GÆA Sociedad Argentina de Estudios Geográficos. Tomo XX. Buenos Aires.

CLAVAL P. (1999). Los fundamentos actuales de la geografía cultural. París :Université de Paris-Sorbonne. Laboratoire Espace et Cultures. Doc. Anál Geogr. 34.

FERNÁNDEZ CHRISTLIEB F. (2006). Geografía Cultural. Hiernaux, A. Lindon (comp.), Tratado de Geografía Humana, México: editorial Anthropos, UNAM, 2006, 220-253.

GIMÉNEZ G. (1996). Territorio y cultura. Estudio sobre las culturas contemporáneas, Vol. II (Núm. 4), Universidad de Colima México, p. 9-30.

GONZÁLEZ C., CÁCERES A. P., AMPUERO C. (2019). Delimitación espacial de unidades territoriales residenciales en la Circunscripción IV - Sección C, Río Gallegos. Informes Científicos Técnicos - UNPA, 11(3), 88-107. https://doi.org/10.22305/ict-unpa.v11.n3.798

GRAVANO A. (2006). La cultura como concepto central de la antropología. Proyecto editorial, Buenos Aires. p. 85-117.

NORAMBUENA M., AMPUERO C., SEGOVIA STANOSS M., CÁCERES A. P. (2015). Barrios de inmigración chilena en Río Gallegos. Una aproximación a la percepción de los habitantes de la ciudad. Informes Científicos Técnicos - UNPA, 7(1), 261-279. https://doi.org/10.22305/ict-unpa.v7i1.124

NORAMBUENA M., AMPUERO C., AMPUERO, I., SEGOVIA STANOSS M., CÁCERES A. P., GONZÁLEZ C. (2018). Migración chilena e identidad territorial en Río Gallegos, Patagonia austral argentina. XI Jornadas Patagónicas de Geografía - I Congreso Internacional de Geografía de la Patagonia Argentino - Chilena. Contradicciones del desarrollo y horizontes alternativos. Universidad Nacional de Comahue. Neuquén. 
ORTEGA C. A. M., CÁCERES A. P. (2018). Posición Geográfica del Campus Universitario de la Unidad Académica Río Gallegos de la Universidad Nacional de la Patagonia Austral en la Tercera franja Residencial de Río Gallegos. Informes Científicos Técnicos - UNPA, 10(1), 30-50. https://doi.org/10.22305/ict-unpa.v10i1.263

REYES TOVAR M., MARTÍNEZ RUÍZ D. T. (2015). La configuración en los territorios migrantes internacionales. Península, Vol. X (Núm. 2), p. 117-133.

SÁNCHEZ AYALA L. (2012). Migración. Geografía humana: Conceptos básicos y aplicaciones, Universidad de los Andes, Colombia, p. 63-80.

SASSONE S. (2007). Migración, territorio e identidad cultural: construcción de "lugares bolivianos" en la Ciudad de Buenos Aires, Población de Buenos Aires, Vol. IV (Núm 6), Octubre, 2007, Buenos Aires, Argentina, p. 9-28.

TAMAYO VÁSQUEZ L. (2011). Identidad cultural en los migrantes. México: MUNAM. Trabajo Social, México DF. 183-194. 